Alma Mater Studiorum - Università di Bologna DEPARTMENT OF ECONOMICS

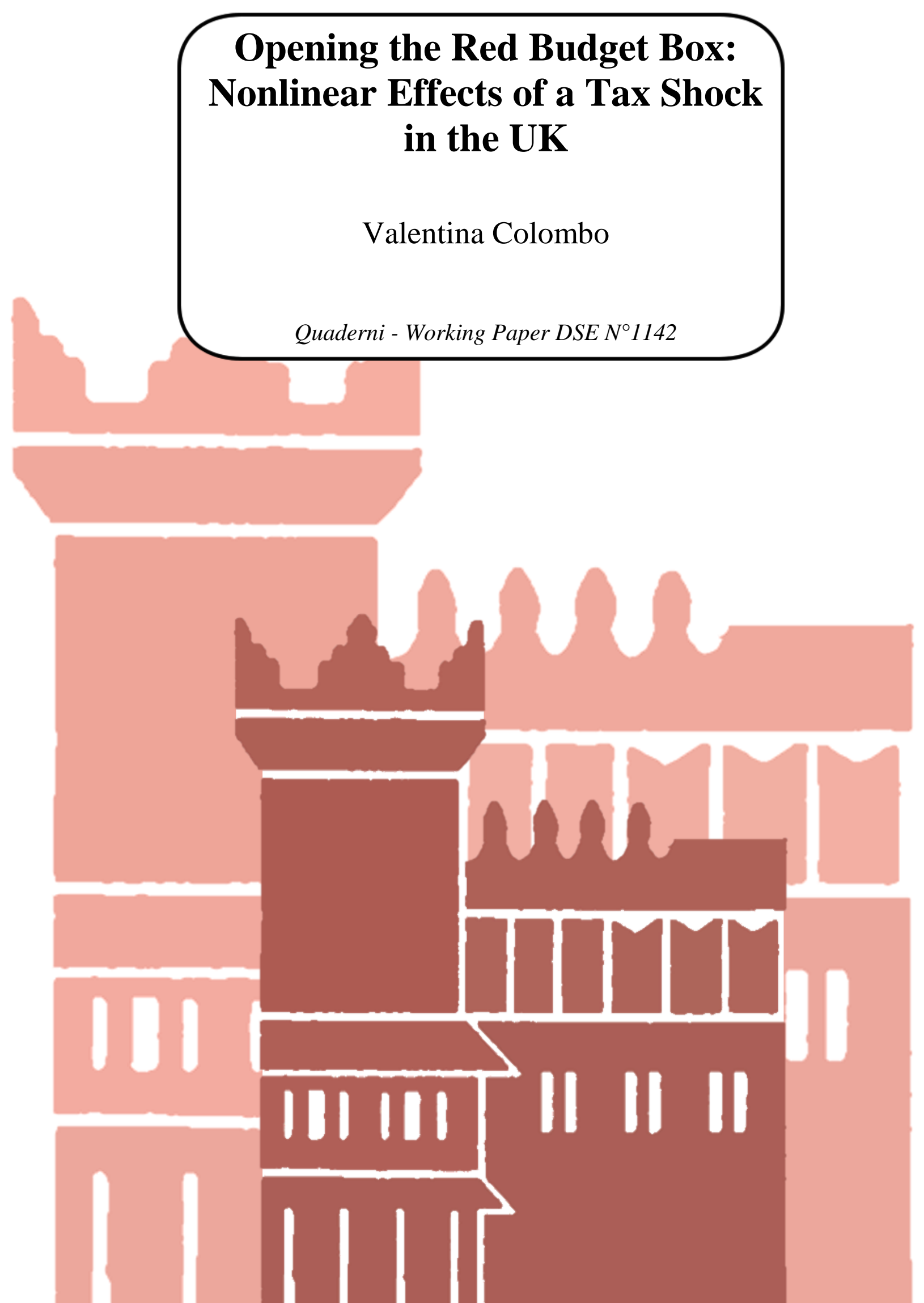




\title{
Opening the Red Budget Box: Nonlinear Effects of a Tax Shock in the $\mathrm{UK}^{*}$
}

\author{
Valentina Colombo ${ }^{\dagger}$ \\ University of Bologna
}

\begin{abstract}
This paper studies the real effects of an exogenous UK tax change in recessions and expansions. The tax shock is identified via the measure proposed by Cloyne (2013). Combining local projection techniques (Jordà, 2005) with smooth transition regressions (Granger and Teräsvirta, 1994), tax policy shock is found to affect UK macroeconomic variables depending on the phase of the business cycle the economy is when tax shock occurs. An exogenous tax cut in recessions triggers a large, persistent, positive, and statistically significant reaction in output, consumption, investment, exports, imports, and government consumption. The results suggest that the output tax multiplier is positive and above one (in absolute value) in recessions but not in expansions. The size and the sign of responses of a number of macroeconomic variables are also found to be state-contingent.
\end{abstract}

JEL classification: E32, E62, H20

Keywords: Fiscal shocks, tax multipliers, business cycle, local projections

\footnotetext{
${ }^{*}$ I would like to thank Emanuele Bachiocchi, Marco Bernardini, Benedetta Bianchi, Monica Billio, Efrem Castelnuovo, Giovanni Caggiano, Luca Fanelli, Lorenzo Forni, Margherita Fort, Riccardo Rovelli, Vincenzo Scrutinio, Timo Teräsvirta, Alessia Paccagnini, Francesco Zanetti, and partecipants at the Padova Macro Talks, the CREATES lunch seminar, the Institute of Economic Policy (UCSC, Milan), the BoMoPaV workshop (Modena, 2015), the SMYE (Ghent, 2015), the IAAE (Thessaloniki, 2015), IIPF (Dublin, 2015), Vienna Macroeconomics Workshop (Vienna, 2015); UCD (Dublin, 2016); CEF (Ottawa, 2019); SIE (Palermo, 2019); Internal seminar DSE (Bologna, 2019) for useful comments and suggestions.

${ }^{\dagger}$ Email: valentina.colombo3@unibo.it; valentina81c@hotmail.it.
} 


\section{Non - Technical Summary}

The Great Recession has reignited the debate on the size of fiscal multipliers. As a result, a growing literature has attempted to quantify the size of the output tax multiplier to assess how appropriate the fiscal intervention has been. However, there is no consensus about the size and the sign of reaction of macroeconomic variables to tax changes. Despite the importance to evaluate whether the effects of a tax shock are asymmetric across the business cycle, the literature focusing on the nonlinear effects of tax changes is scant and it focuses mainly on the US economy.

We contribute to the state of art studying whether an unexpected tax cut in the UK has nonlinear effects on macroeconomic activity over the business cycle. To overcome the identification of tax changes because of the endogeneity problem between tax revenues and GDP, we proxy the UK tax shock relying on the measure constructed by Cloyne (2013). To estimate the effects of tax shocks conditionally on the state of economy and to avoid dealing with some implicit assumptions of the regime-switching model, we combine the Local Projection estimations with smooth transition regressions.

We find that unexpected tax changes exert asymmetric effects on macroeconomic activity depending on the phase of the business cycle the economy is in when the tax change occurs (recessions versus expansions). In particular, the position in the business cycle when the shock occurs statistically affects the sign and the size of the reaction of real variables to tax changes. In recessions, a tax cut has expansionary effects on GDP and its components. We find that the peak output multiplier over three-years is around five, whereas in expansions is below one and not statistically significant. Disentangling the (nonlinear) effects of taxes on the GDP components (consumption, investment, imports, exports, and government consumption), we find that consumption is the key driver of GDP fluctuation along the business cycle. We show that the effects of tax shocks are quantitatively larger in recessions and smaller in expansions than those predicted by a linear framework. A linear estimation overshadows the effects of tax shocks across regimes because it works as an average of the two different effects. Our results are important for a policy standpoint, calling for a tailored use of fiscal policy instruments across the business cycle. 


\section{Introduction}

What are the effects of a tax shock in the UK? Are the effects of a tax shock different across the business cycle (recession versus expansion)? How large is the UK tax multiplier? The Great Recession has reignited the debate on the size of fiscal multipliers. As a result, a growing literature has attempted to quantify the size of the output tax multiplier to assess how appropriate the fiscal intervention has been (i.e., Cloyne, 2013; Mountford and Uhlig, 2009; Romer and Romer, 2010; Favero and Giavazzi, 2012; Perotti, 2012; Mertens and Ravn, 2014). However, there is no consensus about the size and the sign of reaction of macroeconomic variables to tax changes. Blanchard and Leigh (2013) highlight that during the Great Recession the size of fiscal multipliers has been underestimated. This suggests that the effects of fiscal policy tools may vary over time. This paper contributes to the debate studying whether an unexpected tax cut in the UK has nonlinear effects on macroeconomic activity over the business cycle.

Fitting the post-WWII UK data and combining local projection techniques (Jordà, 2005) with smooth transition regressions (Granger and Teräsvirta, 1994), we find that unexpected tax changes exert asymmetric effects on macroeconomic activity depending on the phase of the business cycle the economy is in when the tax change occurs (recessions versus expansions). In particular, the position in the business cycle when the shock occurs statistically affects the sign and the size of the reaction of real variables to tax changes. In recessions, a tax cut has expansionary effects on GDP and its components. We quantify that the peak-level of GDP over three-years is around five in recessions, whereas it is below one and not statistically significant in expansions. Disentangling the (nonlinear) effects of taxes on the GDP components (consumption, investment, imports, exports, and government consumption), we find that consumption is the key driver of GDP fluctuation along the business cycle. We show that the effects of tax shocks are quantitatively larger in recessions and smaller in expansions than those predicted by a linear framework.

These results support the empirical evidence that tax policy changes may generate different outcomes across the business cycle. Tagkalakis (2008), analyzing a panel of nineteen OECD countries, finds that the effects of tax shocks on private consumption are different in recessions and expansions. This asymmetry can be explained by liquidity constraints of households that can be more severe in recessions than in expansions. In the presence of binding liquidity constraints on households, fiscal policy may be more effective in stimulating private consump- 
tion in recessions than in expansions. Moreover, Kaplan and Violante (2014) show that the prevalence of what are known as "hand-to-mouth" consumers, who consume all of their income in each period and whose numbers may be expected to rise in recessions, can generate strong consumption responses to fiscal stimulus. Thus, an expansionary fiscal policy could have Keynesian (positive) effects on consumption in downturns of economic activity when liquidity constraints bind for a larger fraction of the population.

Despite the importance to evaluate whether the effects of a tax shock are asymmetric across the business cycle, the literature focusing on the nonlinear effects of tax changes is scant and it focuses mainly on the US economy (i.e., Sims and Wolff, 2018; Demirel, 2016; Eskandari, 2019). As for the literature dealing with nonlinear effects of tax shocks in the UK, one exception is Baum, Poplawski-Ribeiro, and Weber (2012) which estimate the effects of a tax shock on output relying on a Threshold VAR. They find that the output tax multiplier is close to zero and not statistically significant. ${ }^{1}$

Two issues make our aim challenging. Firstly, the identification of tax changes because of the endogeneity problem between tax revenues and GDP. For instance, tax revenues shocks might trigger output fluctuations, while shocks affecting output might cause revenue fluctuations. To overcome the endogeneity problem, two main approaches have been proposed in the empirical literature. The first one, pioneered by Blanchard and Perotti (2002), relies on structural vector autoregressive (SVAR) analysis in which cyclically adjusted tax revenues are used to proxy tax shocks, and it is based on some assumptions about the implementation lags in fiscal policymaking and on the calibration of the fiscal elasticity. ${ }^{2}$ The second one, the narrative approach proposed by Romer and Romer (2010), identifies an unexpected tax change analyzing written official records and distinguishing tax shocks due to reasons not related to countercyclical concerns

\footnotetext{
${ }^{1}$ Afonso, Baxa, and Slavik (2018) study the nonlinear effects of fiscal policy in Germany, Italy, the UK, and the US. However, using the debt ratio as a proxy for fiscal policy shock, they do not distinguish between revenues and government spending shock.

${ }^{2}$ In the Blanchard and Perotti (2002) approach a change in tax revenues depend on the automatic response of taxes to output and on exogenous tax changes. To purge the tax revenues from automatic stabilizers, they calibrate the elasticity of taxes to output via the OECD method and assumptions proposed by Giorno, Richardson, Roseveare, and van den Noord (1995) and van den Noord (2002). The elasticity of taxes to output is calibrated combining the estimation of elasticity of tax revenues to their tax base with the elasticity of tax base to output. The tax revenues purged by its automatic response to output are the cyclicallyadjusted measure of tax revenues. Then, the calibrated elasticity is used to pin down the relations linking the reduced form residual to the structural shock in a SVAR framework. The identification of structural shocks is recovered relying on some assumptions about the implementation lags.
} 
(exogenous) from those related to them (endogenous). ${ }^{3}$ Several concerns arise from the identification of tax shocks à la Blanchard and Perotti (2002), because it may fail to capture tax shifts that are exogenous. For instance, Romer and Romer (2010) argue that other non-policy movement (i.e., asset and commodity price fluctuation) may affect the cyclically-adjusted revenues and a SVAR may not address the correlations between these factors. Caldara and Kamps (2017) find that the effects of tax shocks on output may be very sensitive to the calibrated elasticity. Furthermore, Auerbach and Gorodnichenko (2012) claim that the calibrated elasticity may vary across the business cycle. Secondly, Ramey and Zubairy (2018) raise another issue that may be behind biased results for the fiscal multipliers in SVAR analysis. The estimated size of fiscal multipliers may be very sensitive to the value of ex post conversion factor, i.e. the ratio of the GDP/fiscal variables, used to convert elasticity into multiplier when the model is estimated including logarithm transformed variables. ${ }^{4}$

Our analysis jointly tackles these two issues. We estimate a (linear) Structural VARs identifying the structural tax shock á la Blanchard and Perotti (2002). We set the elasticity of taxes to output borrowing two coefficient restriction's values proposed by Perotti (2005) and Cloyne (2013), 0.76 and 1.61, respectively. Then, we convert elasticities into multipliers using different ex post conversion factors. The results suggest that tax multipliers (in absolute value) increase in the value of coefficient restrictions (i.e., lower when the coefficient restriction is set to 0.76 and higher when it is equal to 1.61). This result for the UK is in line with the one found by Caldara and Kamps (2008) for the US. They highlight that the effects of tax shock will be biased downward whether the calibrated elasticity is too small. Moreover, estimating two different sample sizes (1963:I-2001:II and 1955:I-2009:IV), we find that increasing the value of the coefficient restriction affects the persistence of tax shocks. Furthermore, the combination of identifying tax shock via coefficient restrictions with ex post conversion factors may lead to another bias on tax multiplier estimates (see Appendix A for details).

To overcome the tax shock identification problem discussed above, we proxy the UK tax shock relying on the measure constructed via narrative-approach and

\footnotetext{
${ }^{3}$ This method has been advocated to identify government spending shocks (see e.g., Ramey and Shapiro, 1998; V. A. Ramey, 2011), fiscal consolidations (see e.g., Devries, Guajardo, Leigh, and Pescatori, 2011; Guajardo, Leigh, and Pescatori, 2014), tax shocks in the US (Romer and Romer, 2010), in Portugal (Pereira and Wemans, 2015), in Germany (Hayo and Uhl, 2014), and in the UK (Cloyne, 2013).

${ }^{4}$ The transformation of variables in logarithm form is a common practice in the VAR literature, but not only. Indeed, Auerbach and Gorodnichenko (2013a) relying on Local Projection regressions use log-transformed variables.
} 
proposed by Cloyne (2013), whereas to avoid the ex post conversion factor one we define the variables as in Hall (2009) and in Barro and Redlick (2011). To estimate the effects of tax shocks conditionally on the state of economy and to avoid dealing with some implicit assumptions of the regime-switching model, we combine the Local Projection (Jordà, 2005) estimations with smooth transition regressions (Granger and Teräsvirta, 1994). ${ }^{5}$

Our main results show that the impact of tax shocks on the macroeconomic variables is asymmetric over the business cycle. Researchers disagree over the (linear) effects of a tax shock in the UK. For instance, Perotti (2005), relying on the Blanchard and Perotti (2002) approach, finds that a tax cut has small but recessionary effects on output, opposite to the conventional wisdom. Cloyne (2013), identifying the tax shock à la Romer and Romer (2010), finds the opposite results: an unexpected decrease in taxes has positive and statistically significant effects on output ( 2.15 over three years). We reconcile these differences considering the phase of the economy in which tax shock occurs. The difference of the results across regimes (recessions and expansion) lies in the relative position of the AD-AS curves. To rationalize these results we consider an AS curve which is relatively flat before the point of full employment level of national income, and then it becomes almost vertical afterward. In expansions, the aggregate demand curve is in the steeper part of the aggregate supply curve and the effects of tax shocks on output are small. Conversely, in recessions the aggregate demand curve is in the flatter part of the aggregate supply curve, and therefore the variation of output to taxes is larger in recessions than in expansions. We show that the effects of such shocks are quantitatively different than those predicted by a linear framework. A linear estimation overshadows the effects of tax shocks across regimes because it works as an average of the two different effects. Our results are important for a policy standpoint, calling for a tailored use of fiscal policy instruments across the business cycle.

A battery of robustness checks, dealing with alternative specifications, confirms the asymmetric effects of a tax shock on GDP and its components.

Our paper is closely related to studies on the UK economy, i.e. Perotti (2005), Cloyne (2013), and Baum, Poplawski-Ribeiro, and Weber (2012). There are differences between their contributions and ours in terms of identification of tax

${ }^{5}$ The use of single-equation technique in a nonlinear framework has been also advocated by Auerbach and Gorodnichenko (2013a; 2013b; 2017), Owyang, Ramey, and Zubairy (2013), Ramey and Zubairy (2018), Ben Zeev and Pappa (2017), Leduc and Wilson (2012) and others as an simple alternative to the VARs. 
shocks and model specifications. First, Perotti (2005) relies on the Blanchard and Perotti coefficient restriction scheme, whereas we identify the tax shock via narrative tax shock measure provided by Cloyne (2013). Cloyne (2013) studies the linear responses of macroeconomic variables tax shocks. Conversely, we investigate the impact of tax shocks conditionally on the phase of the business cycle the economy is when tax shocks occur. Second, Baum, Poplawski-Ribeiro, and Weber (2012) study the effects of tax shocks in a nonlinear specification and identifying the structural shock á la Blanchard and Perotti (2002). Differently, we identify the tax shocks via the narrative measure proposed by Cloyne (2013), and to estimate the effects of tax shocks on output, but also on its components, we rely on a nonlinear version of the Local Projection (Jordà, 2005) technique.

Our work contributes to growing empirical literature on the state-dependent tax multipliers (i.e., Sims and Wolff, 2018; Demirel, 2016; Eskandari, 2019). Focusing on the US, such studies find that output tax multipliers are procyclical (higher in good times than in bad times). They show that the procyclicality of output tax multipliers in the US is driven by the procyclicality of the investment. Conversely, we find that a tax cut in the UK is most stimulative in recessions than in expansions. Moreover, the state-dependent reaction of the UK output is mainly driven by the reaction of consumption, the bigger component of aggregate demand. Thus, our results are in line with the results found by Tagkalakis (2008) and Kaplan and Violante (2014).

Finally, our work is also related to existing wider empirical literature on tax multipliers (i.e., Blanchard and Perotti, 2002; Barro and Redlick, 2011; Mountford and Uhlig, 2009; Romer and Romer, 2010; Mertens and Ravn, 2014; Ghassibe and Zanetti, 2019), and in particular to the one pioneered by Romer and Romer (2010) based on the identification of exogenous tax change via the narrative approach (see, V. Ramey, 2019 for a recent survey).

The remainder of this paper is organized as follows. Section 2 presents the linear and nonlinear specifications. Section 3 reports the results from the linear and nonlinear estimations. Section 4 shows the robustness checks, whereas section 5 concludes. 


\section{Data definition and Methodology}

\subsection{Linear Model}

We estimate the effects of a tax shock on UK macroeconomic aggregates relying on the Local Projection (LP) technique introduced by Jordà (2005). LP allows us to project the value of the dependent variable shifted $h$ periods ahead on the information set available at time $t$. Thus, those projections are local to each horizon.

Consider a $h$ set of regressions for $h=0,1,2 \ldots H$ for each variable of interest, $\tilde{X}_{t+h}:$

$$
\tilde{X}_{t+h}=\alpha_{h}+\zeta_{h}+B_{L h}(L) y_{t-i}+\theta_{L h} \epsilon_{t}^{\text {Cloyne }}+u_{t+h}
$$

where $\alpha$ and $\zeta$ are the constant and the linear trend, $B_{L h}$ is the coefficient matrix at each horizon $h$ and $y_{t-i}$ is the vector of control variables which include $i$ lags of variables that usually enter in a "fiscal" VAR, such as the log real percapita terms of the government spending, GDP and tax revenues. ${ }^{6}$ To avoid the degree of freedom constraints due to lag length and dimension of covariate vector on the maximum horizon $h$ (Jordà, 2005), we opt for a parsimonious specification of $y_{t-i}$ which includes four lags for each variable, as in Auerbach and Gorodnichenko (2013a). ${ }^{7}$ The tax shock variable $\left(\epsilon_{t}^{\text {Cloyne }}\right)$ in equation (1) is the tax change measure proposed by Cloyne (2013). It is constructed via the narrative approach proposed by Romer and Romer (2010) and allows to separate exogenous components of tax changes from the endogenous ones (i.e., tax policy change not due to countercyclical concern versus these due as response to the macroeconomic fluctuations). In particular, Cloyne's tax shock measure includes four categories of exogenous tax changes. ${ }^{8}$ Firstly, it includes "long-

${ }^{6}$ Different model specifications have been proposed in the tax literature. For instance, Romer and Romer (2010) regress the dependent variable (GDP) on the contemporaneous value and 12 lags of their tax measure. Cloyne (2013) includes 12 lags of his tax measure, as in Romer and Romer (2010), but in an "augmented" VAR which includes the consumption, investment and GDP equations, as in Mertens and Ravn (2014). Favero and Giavazzi (2012) include only the contemporaneous value of the Romer and Romer (2010) tax shock in a VAR which models, among variables, also the revenues one. Our specification is very close to the one in Favero and Giavazzi (2012). However, we address the issue of different lag length of tax shocks to be included in our specification in the robustness check section.

${ }^{7} \mathrm{~A}$ specification including four lags is quite standard in the SVARs estimated on quarterly data.

${ }^{8}$ The source for revenue estimates are the Financial Statement and Budget reports and the official parliamentary records. 
run" economic reforms not aimed at offsetting macroeconomic fluctuations. The second component is the "ideological" tax changes adopted for political reasons, whereas the third one refers to the "external change" (for example, imposed from court judgments or European directives). The fourth component is the "deficit consolidation" not driven by current movement in deficit or as a consequence of other macroeconomic shock but, for example, to anchor the Government's credibility. The series is aggregated according the implementation date to avoid contemporaneous endogeneity of tax revenue to GDP. The changes in revenues are normalized by the GDP and expressed as percentage. Then, a change in Cloyne's measure will reflect the forecast "full year" change in revenues in each quarter. The fact of having an estimate of the unanticipated fiscal shock enables us to employ a uniequational approach to compute dynamic responses of a given macroeconomic variable of interest. In other words, we need not appeal to a VAR framework to identify the effects of an exogenous variations in taxes (for a comparison between VAR and LP impulse responses, see Plagborg-Møller and Wolf, 2019). The advantage of the uniequational approach is that it is less prone to model misspecification, hence - all else being equal - it reduces the risk of producing biased impulse responses. For further discussions on this approach, see Alesina, Favero, and Giavazzi (2014). The effects of a tax change $\left(\epsilon_{t}^{\text {Cloyne }}\right)$ on each variables of interest $\left(\tilde{X}_{t+h}\right)$ are captured by parameter $\theta_{L h}$ in equation (1). Thus, the IRFs are constructed as a sequence of estimated $\left\{\theta_{L h}\right\}_{h=0}^{20}{ }^{9}$

The main advantage of this methodology for the tax multiplier estimations is that it does not require that the left-hand side variables in equation (1) should be specified in the same form as the right-hand side variables. This property allows to define each dependent variable of interest $\tilde{X}_{t+h}$ as in Hall (2009), Barro and Redlick (2011) and Owyang, Ramey, and Zubairy (2013). In particular, $\tilde{X}_{t+h}$ is defined as following:

$$
\tilde{X}_{t+h} \approx\left(\ln X_{t+h}-\ln X_{t-1}\right) \frac{X_{t-1}}{G D P_{t-1}}
$$

where $\left(\ln X_{t+h}-\ln X_{t-1}\right)$ refers to the accumulated change from time $t$ - 1 to $t+h$, whereas the ratio $X_{t-1} / G D P_{t-1}$ converts ex ante the percent change to pound change at each point on time, as in Owyang, Ramey, and Zubairy (2013). Thus, this specification overcomes the problem of ex post conversion factors, and avoid bias in the estimation of tax multipliers.

\footnotetext{
${ }^{9}$ Notice that the proxy of tax shock is scaled by the nominal GDP. It means that estimated coefficients $\theta_{h}$ have the familiar interpretation of tax multipliers.
} 
Jordà's method implies the serial correlation in the error terms. To account for it, we computed confidence intervals relying on the block bootstrap (Politis and Romano, 1992). ${ }^{10}$ We rely on quarterly data spanning from 1955Q1-2009Q4. The beginning of the period is motivated by the availability of the quarterly data, whereas the end by the availability of the proxy for tax changes. Table 1 summarizes the variables used and their sources.

\subsection{The Nonlinear Model}

Are the effects of a tax cut state-dependent? Following Auerbach and Gorodnichenko (2013a; 2013b; 2017) we study the nonlinear effect of a fiscal shock on variables of interest combining the LPs (Jordà, 2005) with smooth transition regressions (Granger and Teräsvirta, 1994). The response of dependent variables $\tilde{X}_{t+1}$ to a tax shock is estimated by the following regression:

$\tilde{X}_{t+h}=\zeta_{h}+F\left(z_{t_{-} i}\right)\left(\alpha_{R, h}+B_{R, h}(L) y_{t-i}+\theta_{R, h} \epsilon_{t}^{\text {Cloyne }}\right)+\left(1-F\left(z_{t_{-} i}\right)\right)\left(\alpha_{E, h}+B_{E, h}(L) y_{t-i}+\theta_{E, h} \epsilon_{t}^{\text {Cloyne }}\right)+u_{t+h}$

where R stands for Recession and E for Expansion. Each variable of interest $\tilde{X}_{t+1}$ is projected on the same vector of covariates $y_{t-i}$ of the linear specification, and $B_{R, h}$ and $B_{E, h}$ refer to coefficient matrices of the recessionary and expansionary phase, respectively. The lagged variables in $y_{t-i}$ are used to control for the history of the shock, as in Auerbach and Gorodnichenko (2013a). We allow all of the coefficients to vary across the business cycle, except for the trend term. The effect of a tax shock on $\tilde{X}_{t+h}$ at horizon $h$ is captured in recessions by $\theta_{R, h}$, whereas in expansions by $\theta_{E, h}$.

As in Auerbach and Gorodnichenko (2013a; 2013b; 2017), the transition of $\tilde{X}_{t+1}$ from one regime to another is governed by a logistic function that depends on $z_{t}$ :

$$
F\left(z_{t}\right)=\frac{\exp \left(-\gamma z_{t}\right)}{1+\exp \left(-\gamma z_{t}\right)}, \quad \gamma>0, \quad z_{t} \sim N(0,1)
$$

The transition function in (4) is a monotonically increasing function of $z_{t}$, where $F$ is a continuous transition function bounded between 0 and 1 and $z_{t}$

\footnotetext{
${ }^{10}$ The procedure used implies: 1 ) run a regression at time $\mathrm{t}+\mathrm{h}$, obtain the estimators and calculate the fitted value and residuals; 2) resample a block of residuals (1) with replacement and calculate the bootstrapped dependent variable; 3) run the regression with the bootstrapped dependent variables and the original regressors; 4) repeat B-times by going back to 2). In our linear and nonlinear estimation $\mathrm{B}=1,000$ and $\mathrm{l}=10$.
} 
is the transition variable. The slope parameter $\gamma$ determines the smoothness of the change between 0 (strong expansions) to 1 (strong recessions), and the identification restriction is that $\gamma>0$. If $\gamma \rightarrow \infty$ in (4), then equation (3) becomes a two-regime switching regression model.

Before estimating equation (3) for each variable of interest $\tilde{X}_{t+h}$, we formally test for the presence of nonlinearities. Linearity is tested replacing the transition variable $F\left(z_{t-i}\right)$ by the third order Taylor series approximation around $\gamma=0$, as suggested by Lukkonen, Saikkonen, and Teräsvirta (1988).

We test linearity as following:

$$
X_{t}=w_{t} \beta_{0}^{\prime}+\left(\tilde{w}_{t} z_{t-i}\right)^{\prime} \beta_{1}+\left(\tilde{w}_{t} z_{t-i}^{2}\right)^{\prime} \beta_{2}+\left(\tilde{w}_{t} z_{t-i}^{3}\right)^{\prime} \beta_{3}+u_{t}
$$

where vector $w_{t}$ contains four lags of covariates (log-real GDP, government spending, revenues) and the contemporaneous value of tax shock $\left(\epsilon_{t}^{\text {Cloyne }}\right)$. Testing the null hypothesis of linearity versus nonlinearity is equivalent to perform an $\operatorname{LM}\left(\chi^{2}\right)$ test of $H_{0}^{\prime}: \beta_{\iota}=0, \iota=1,2,3$, against $H_{1}^{\prime}$ : at least one $\beta_{\iota} \neq 0$. We perform the linearity test plugging in $X_{t}$ the variable of interest and in $z_{t-i}$ each potential transition variable, such as the lagged $(t-i)$ standardized backwardlooking moving average (MA) over $(j)$ quarter(s) of the output growth rate with $i \in I=1, . ., 5$ and $j \in J=2, \ldots 8$. The choice of $i$ is justified to avoid that tax shocks may have some contemporaneous feedback on the state of economy. Notice that all the transition variable candidates have been standardized to be comparable. Table 2 reports the p-value (multiplied by 100) of linearity tests. The tests suggest a clear rejection of the null hypothesis of linearity in favor of a specific nonlinear specification, such as the smooth transition one. We choose for the variable of interest the transition variables $M A(j)$ lagged at time $t$ - $i$ corresponding to the smallest p-value (Teräsvirta, 1988). That because whether there is a correct transition variable among the different alternatives, the power of the test is maximized against it. Table 2 highlights that the nonlinearity of the GDP, consumption, investment, exports is governed by a $M A(2)$ lagged at $t$-1, whereas that one of import and government consumption by a $M A(2)$ lagged at time $t-5$.

Then, we calibrate the smoothing parameters $\gamma$ to match the probability of being in recession obtained applying the BBQ algorithm on the logarithm of the real GDP (more details in Appendix B). We define a recessionary regime a period for which $F\left(z_{t}\right) \geq 0.85 \approx 0.15$. It means that the economy spends about $15 \%$ of the time in the recessionary state and $85 \%$ of the time in the expansionary one. ${ }^{11}$

\footnotetext{
${ }^{11}$ The values of $\gamma$ are in line with estimates obtained regressing in a logit model the dummy
} 
This implies setting $\gamma=1.7$. Figure 1 plots Cloyne's tax change measure versus the recessionary (shaded area) and expansionary phases, ${ }^{12}$ whereas figures 2 and 3 refer to the transition variable $z_{t}$ and transition function $F\left(z_{t}\right)$, respectively. ${ }^{13}$

Notice that one important advantage of the LPs is that the impulse responses incorporate the average transitions of the economy from one regime to another. According to Ramey and Zubairy (2018), the estimated coefficients in equation (3) depend on the characteristic of the economy from time $t$ to $t+h$, given the initial conditions (the tax shock, the initial state of the economy, and the control variables). Since the control variables in equation (3) do not change at each horizon $h$, then the estimated coefficients on the covariates capture the average transition of the economy from one state to another occurring in the sample.

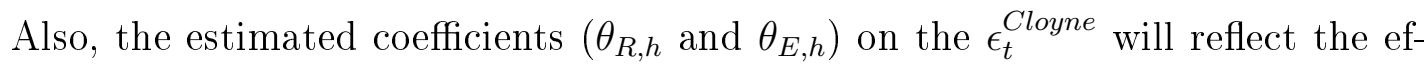
fects of the tax shock on the future state of economy. For example, suppose that a tax shock has negative effects on output in recessions and positive in expansions, and a tax shock occurs in an expansionary period bringing the economy in a recessionary one. Then, the estimated parameters $\theta_{E, h}$ will incorporate the transition of the economy from the expansionary to the recessionary regime changing its values from positive to negative. ${ }^{14}$

\section{Results}

\subsection{Output Response}

Figure 4 depicts the responses of GDP to an exogenous decrease in taxes equal to $1 \%$ of GDP estimated via the linear and nonlinear specifications. Notice that in the linear specification the IRFs are constructed as a sequence of estimated

variables $(\mathrm{R}=1$ and $\mathrm{E}=0)$ obtained by the $\mathrm{BBQ}$ algorithm on transition variables (results available upon request).

${ }^{12}$ The correlation between the tax shock measure and $F\left(z_{t}\right)$ or $\left(1-F\left(z_{t}\right)\right)$ is equal to zero.

${ }^{13}$ In the transition function $F\left(z_{t}\right)$ (figure 3), the frequency of non-alterning points is high. It depends on the characteristic of the transition variable $z_{t}$. This is in line with Harding (2008) which show that in the UK "the frequency of non-alterning points is four times higher than the US". Of course, if $z_{t}$ has some non-alterning points, this characteristic will be amplified in the transition function $F\left(z_{t}\right)$ in which those points are bounded between zero and one.

${ }^{14}$ Using a SVAR we can account for this feedback only through Generalised IRFs, as in Caggiano, Castelnuovo, Colombo, and Nodari (2015). As noted by Owyang, Ramey, and Zubairy (2013), the difference between GIRFs and LPIRFs is based on how the two IRFs account for this feedback: in the GIRFs using the response at time $t$ - 1 to estimate the response at time $t$, whereas in LPs computing the average $h$-period-ahead value forecast given the information set at time $t$. See Owyang, Ramey, and Zubairy (2013) for a careful discussion and comparison between the GIRFs and the LPIRFs. 
$\left\{\theta_{L h}\right\}_{h=0}^{20}$, whereas in recessions and expansions as a sequence of $\left\{\theta_{R h}\right\}_{h=0}^{20}$ and $\left\{\theta_{E h}\right\}_{h=0}^{20}$ one, respectively. The blue lines denote the IRFs in expansions, the red lines the ones in recessions, whereas the black line the reaction of output estimated via the linear model. ${ }^{15}$ The first column of figure 4 compares the linear and state-dependent responses. For ease of comparison, we only report the IRFs. The second and third column report the IRFs and the $16^{\text {th }}$ and $84^{\text {th }}$ percentiles of the distribution of the responses at each horizon. The impulse responses are expressed as percent changes of GDP.

Focusing on a linear estimation, an exogenous tax cut has a positive, statistically significant, and persistent effect on output. The GDP increases on impact by $0.5 \%$ and peaks at $1.8 \%, 17$ quarters after the initial shock, then slowly goes back to its steady state. Turning to a recessionary regime, a change in taxes has positive effects on GDP. Following an unexpected tax cut, the output increases on impact by $1.2 \%$ and the peak-level is around 5 and comes after two years, then gradually returns to the steady-state. Conversely, in expansions the reaction of output to tax shock is not statistically significant for the first sixteen quarters.

Our findings show that the effect of tax shocks varies across the business cycle. The linear IRFs highlight that a linear estimation overshadows the asymmetric effects of macroeconomic variables to tax shocks as it works averaging up the two different effects across the business cycle. The linear estimation tends to underestimate the real effects of a tax shock, whereas it overestimates the ones in expansions.

Overall, our results predict asymmetric effects of tax shocks across the business cycle. The results can be read through the lenses of the AD-AS model. Suppose that the economy is producing at its full employment level of natural income and the aggregate supply curve is flat and becomes steeper and steeper and vertical at this point. If the economy starts from its equilibrium level and there is an expansionary phase, the aggregate demand shifts rightwards and the impact on output will be small, since the aggregate supply is almost vertical. The only effect is on prices. If the economy is in expansions and the government decreases taxes, the new aggregate demand curve will shift toward right yet in an even more vertical part of the aggregate supply curve.

If the economy is in recession, the original aggregate demand shifts on the left. In this case, the movement of the aggregate demand is happening in a point of the aggregate demand that lies flatter than the one considered before. Suppose

\footnotetext{
${ }^{15}$ See Auerbach and Gorodnichenko (2013a), note 6, for analytic comparison between the LPIRFs and the conventional IRFs.
} 
the economy is in a recessionary phase and the government reduces taxes. This causes a movement toward right of the aggregate demand curve and such shift will affect output stronger than before. The positive effects on output of this policy intervention will be in absolute value stronger than the same policy intervention that happens during expansions. The difference between the two phases of the economy (recessions and expansion) lies in the relative position of the AD-AS curves. In expansions, the AD curve is in the steeper part of the AS curve and the effects on output are small. Conversely, in recessions the AD curve is in the flatter part of the AS curve, and therefore the $\left|\frac{\Delta Y}{\Delta T}\right|^{\operatorname{Rec}}>\left|\frac{\Delta Y}{\Delta T}\right|^{\operatorname{Exp}}$.

\subsection{Transmission mechanism: output components}

According to our baseline results, an exogenous tax cut has larger effects (in absolute value) on output in recessions than in expansions. Which variable drives output fluctuation? To answer this question, we define each component of GDP (consumption, investment, export, import, and government consumption) as in (2) and then we plug each of them in equation (1) and (3). Before estimating equation (3), we formally test for the presence of nonlinearities for each dependent variable. Table 2 confirms that there is a clear rejection of linearity for each component of output in favor of a specific nonlinear specification, such as the smooth transition regressions.

Figure 5 depicts the responses of GDP components to exogenous decrease in taxes equal to $1 \%$ of GDP. Once again, in the linear specification the IRFs are constructed as a sequence of estimated $\left\{\theta_{L h}\right\}_{h=0}^{20}$, whereas in recessions and expansions as $\left\{\theta_{R h}\right\}_{h=0}^{20}$ and $\left\{\theta_{E h}\right\}_{h=0}^{20}$ one, respectively. The first column of figure 5 compares the linear and the state-dependent responses for each variable of interest. The second and third column reports the IRFs for the recessionary and expansionary case and the $16^{\text {th }}$ and $84^{\text {th }}$ percentiles of the distribution of the responses of each variable at each horizon.

Focusing on the recessionary regime, an exogenous decrease in taxes has positive effects on output components. In particular, the impact response of private consumption is positive (1\%), hitting its peak value (4.5\%) 8 quarters after the shock occurs, then goes back to its steady-state. The investment (gross fixed capital formation) increases and reaches its peak at $1.3 \%$. Tax shock is found to affect statistically and positively exports and imports. On impact, imports increase by $0.3 \%$ and, after it peaks at around $1.7 \%$, then gradually goes back to zero. The response of government consumption in the first three 
quarters is not statistically significant. However, when it peaks at $1.2 \%$, the response becomes statistically significant.

Next, we look at the response of macroeconomic aggregates to a tax shock in expansions. An unexpected tax cut has not statistically significant effects on consumption and investment for the first twelve quarters. After this, the reaction becomes positive and statistically significant. Tax shock is found to not affect statistically the impact reaction of imports. Conversely, the reaction of exports is statistically significant and negative. Government consumption reacts statistically significant and negatively to a tax shock decreasing on impact by $-0.2 \%$ and, after reaching its trough at $-1.1 \%$, then gradually goes back to zero.

Turning to the linear estimation results, the private consumption increases on impact by $0.6 \%$ hitting a peak of $2.1 \%$, sixteen quarters after the shock occurs. Afterward, consumption gradually returns to its steady-state. Investment increases on impact by a small amount $(0.1 \%)$ and hits the peak $(0.5 \%)$ in the 4th quarter. Tax shock does not affect exports in the short-run, whereas it has positive and persistent effects on imports. Our estimations predict a positive reaction of government consumption, albeit small.

Statistical evidence in favor of state-dependent impulse responses. According to our estimation, the effects of tax shocks are state-dependent. To statistically support our results, we test the difference between the reactions of macroeconomic variables estimated under recessionary and expansionary regimes. The empirical density of the difference between IRFs is based on 1,000 realizations of such differences for each horizon $h$. Figure 6 plots the median of the difference with the 16th and 84th percentile error bands for GDP and its components. If the value of zero is not included in the 16th and 84th percentile error bands, then there will be evidence of nonlinearity. Overall, figure 6 confirms that the effects of tax shock in the UK are statistically significant different across the business cycle.

These findings accord with the analysis of Tagkalakis (2008): since the fraction of liquidity constrained households is likely to increase, the decrease in taxes increases their disposable income. An expansionary fiscal policy increasing the disposable income of households has positive wealth effects, and therefore households consume more. Conversely, in expansions the positive effect of a tax cut is counteracted by a decrease in government consumption. It turns out that the reaction of private consumption is not statistically significant for the first 12 quarters. With regard to output, the results have some similarities to con- 
sumption. In recessions, the shock increases output, but this effect disappears in expansions. Since in our sample consumption represents $57 \%$ of GDP, the reaction of output is likely to be driven by the reaction of consumption. This tendency also holds in expansions. Turning to investment, our results show that a decrease in taxes has positive effects, both in recessions and in expansions. However, the dynamics are different. In recessions, the effect of tax changes impact investment within two years the shock occurs, whereas in expansions after that period. The decrease in taxes increases the business profits and the investment financed by those profits. The response of imports and exports is asymmetric across the business cycle. In recessions, imports strongly increase likely because of the increase in income, and therefore in domestic demand for foreign goods. The reaction of exports may depend on the exchange rate ${ }^{16}$ and on external factors. Interestingly, exports decrease in expansions, whereas the reaction of imports is not statistically significant in recessions.

Interesting, also when we focus on components of GDP the linear estimation overshadows the asymmetric effects of macroeconomic variables to tax shocks as it works averaging up the two different effects across the business cycle.

\subsection{Tax Multipliers}

How large are tax multipliers in the UK? Are tax multipliers state-dependent? From columns (1) to (3) of table 3 reports the mean, the peak and the cumulative tax multipliers for the recessionary, expansionary and linear case. ${ }^{17}$ Bold

\footnotetext{
${ }^{16}$ Notice that the UK has experimented different exchange rate regimes in the postwar period. Indeed, until 1972 it was part of the Bretton Woods system. From 1972 to 1990 it adopted a semi-managed floating regime. From 1990 to 1992 the UK was part of the European Exchange Rate Mechanism. From 1993 the UK has adopted a floating exchange rate regime. Studying the reaction of the exchange rate to a tax shock is already in the agenda. However, it suffices here to say that focusing on the subsample 1972-2009 -according to Ilzetzki, Mendoza, and Végh (2013) can be considered a flexible exchange rate regime- and adding among the covariates the real exchange rate does not affect the results.

${ }^{17}$ The mean is computed as $\frac{1}{H} \sum_{h=1}^{H} \Delta \tilde{X}_{t+h}$, the peak as $\Delta \tilde{X}_{t+h} \max _{h=1 \ldots H}\left\{\Delta \tilde{X}_{t+h}\right\}$. The cumulative multipliers is computed as $\frac{\sum_{h=1}^{H} \Delta \tilde{X}_{S, t+h}}{\sum_{h=1}^{H} \Delta \tilde{Y}_{S, t+h}}$ with $\mathrm{S}=\{L, R, E\}$ and $H=12$. To obtain the estimated $\theta_{S h}$ coefficients of the variable in the denominator (tax revenues), we transform the tax revenues series as in (2), plug it in equation (1) and (3) and we run $h$ set of regressions. After having obtained the distribution of the responses of the tax revenues, we compute the tax multipliers dividing the sum of the distribution of the responses of each variable of interest $\left(\theta_{S h}\right)$ until horizon $H$ to the counterpart distribution of the responses of revenues $\left(\theta_{S h}\right)$. The cumulative tax multipliers, last column in table 3 , are negative since any tax cut that increases output causes tax revenues to decrease. Multiplying the ratio of such change (plus in the numerator and minus in the denominator), it translates in negative multipliers.
} 
numbers indicate that multipliers are statistically significant with the 16th and 84th percentile error bands.

The results show the effects of tax shock are different conditional on the state of the economy. The multipliers in recessions are unequivocally larger in absolute value than the multipliers associated with expansionary periods. In recessions, all multipliers are always larger than one (in absolute value) and statistically significant. The peak multiplier is around 5 and it occurs at the $8^{\text {th }}$ quarter. In expansions, output tax multipliers are close to zero and not statistically significant. Turning to the linear tax multipliers, results show that the output tax multipliers work as an average between the estimated ones in recessionary and expansionary times.

Statistical evidence in favor of state-dependent tax multipliers. According to our estimation tax multipliers are state-dependent. To the best of our knowledge, only Baum, Poplawski-Ribeiro, and Weber (2012) have studied the nonlinear effect of tax shock in the UK (via a Threshold VAR). They apply the Blanchard and Perotti (2002) identification strategy and find an output multipliers below 0.4 (in absolute value) that are not statistically significant different across regimes (positive output versus negative output). ${ }^{18}$

To statistically support whether tax multipliers are different across regimes, we test the difference between the multipliers estimated under recessionary and expansionary regimes. ${ }^{19}$ If the value of zero is not included in the 16 th and 84th percentile error bands (not reported in the table for sake of simplicity but available upon request), then there will be evidence of state-dependent tax multipliers. For ease of exposition, whether the multipliers are statistically significant different in recessions and expansions, we set an asterisk on the coefficient related to the recessionary period in table 3 . Overall, there are statistically evidences that tax multipliers in UK are state-dependent.

\footnotetext{
Alternatively, as in Sims and Wolff (2018), we can multiply by minus one to make multipliers positive to easily compare those with the government spending multipliers.

${ }^{18}$ Baum, Poplawski-Ribeiro, and Weber (2012) identify the tax shock in two steps. First of all, they eliminate from the tax revenue series the cases of revenues changes not related to fiscal policy decisions (i.e., movement in commodity price and asset). To this aim, they compare the IMF (2010) action-based measure with the cyclical adjusted primary balance (CAPB) and whether the divergence between the two measures was large, then revenue changes unrelated to fiscal policy decisions are removed from the revenue series. Doing that, the revenues series reflects the change in output and fiscal policy decisions. Secondly, to identify a structural tax shock unrelated to movement in output they apply the Blanchard and Perotti (2002) procedure.

${ }^{19}$ The empirical density of the difference between multipliers is based on 1,000 realizations of such differences for each horizon $h$.
} 
Thus, evaluating tax multipliers in a linear framework may lead to overestimate the effects of decreasing taxes in expansions and underestimated the ones in recessions. Blanchard and Leigh (2013) highlight that for the recent recession the size of fiscal multipliers has been underestimated. We highlight that macroeconomic conditions can affect fiscal multiplier estimates.

Our results are related to the literature quantifying output tax multipliers. The sign and the size of reaction of GDP estimated by the linear specification are in line with the ones found by the recent literature. For example, Cloyne (2013) for the UK and Barro and Redlick (2011) and Romer and Romer (2010) for the US find that tax multipliers are negative and above one. However, we estimate a peak tax multiplier in recessions around 5, twice larger than the UK (linear) one estimated by Cloyne (2013), but close to the one estimated for the US by Mountford and Uhlig (2009).

Interesting, when we rely on a nonlinear estimation output tax multipliers are found to be qualitatively different with respect to the growing literature focusing on the US state-dependent tax multipliers. In particular, Sims and Wolff (2018) use a medium-scale dynamic stochastic equilibrium model to show that tax multipliers in the US are procyclical. In other words, tax multipliers are in absolute value larger in expansions than in recessions. Eskandari (2019) and Demirel (2016) confirm that tax multipliers are larger during times of low employment than times of high employment. Notice that they focus on the US and, as highlighted by the same authors, the procyclicality of output tax multipliers in the US is driven by the procyclicality of the investment. Conversely, we find that the nonlinear effects of a tax cut on the UK GDP are mainly driven by the reaction of consumption, the bigger component of aggregate demand, that is larger in recession than in expansions. Thus, our results are in line with the results found by Tagkalakis (2008). He finds that show that during a recession the fraction of liquidity constrained household increase and an expansionary fiscal policy is more effective in boosting private consumption in recessions than in expansions. Moreover, Kaplan and Violante (2014) show that the prevalence of what are known as "hand-to-mouth" consumers, who consume all of their income in each period and whose numbers may be expected to rise in recessions, are able to generate strong consumption responses to fiscal stimulus. 


\section{Robustness checks}

Our results highlight that the effects of tax shock on the UK GDP are statedependent. In this section, we check the robustness of our findings.

Alternative measure of tax shocks. We have identified the tax shock in equation (1) and (3) via the contemporaneous value of the Cloyne tax shock $\left(\epsilon_{t}^{\text {Cloyne }}\right)$. This specification is close to the Favero and Giavazzi (2012) one, given that we also include in vector $y_{t}$ lagged values of revenues. ${ }^{20}$ The reasons for this specification are twofold. Firstly, we treat $\epsilon_{t}^{\text {Cloyne }}$ as an observable and exogenous shock to revenues. ${ }^{21}$ Secondly, this specification allows us to preserve degrees of freedom given our sample size. Notice that we have extended the linear analysis to the nonlinear one. Whether the inclusion of lagged values of the $\epsilon^{\text {Cloyne may }}$ be not problematic in terms of degree of freedom in the linear specification, it will be in the nonlinear one since the parameters to be estimated double.

As highlighted by Cloyne (2013), the majority of tax changes captured by the narrative measure $\epsilon_{t}^{\text {Cloyne }}$ are announced and implemented within the same quarter. However, lagging the tax shock allows accounting for the possibility of a partial revision to tax shocks. Another issue rises since tax shock is constructed on the base of policymakers' intentions. For instance, policymakers may declare that tax changes are made for a reason unrelated to movements in macroeconomic variables, while in reality they are concerned about these. We tackle the two above issues by regressing the $\epsilon_{t}^{\text {Cloyne }}$ on its own 12 lags and on the covariates that enter in vector $y_{t}$. Then, we select the number of terms of the MA(p) process by checking the statistical significance of such terms. It turns out that $\mathrm{p}=4$ is the last significant term of the process. Thus, we identify the tax shock via the residual obtained regressing $\epsilon_{t}^{\text {Cloyne }}$ on its own 4 lags and on the covariates that enter in vector $y_{t}$. In this way, we identify a residual tax shock purged from the potential revision in tax changes and movements of some macroeconomic variables. The correlation between the $\epsilon_{t}^{\text {Cloyne }}$ and the alternative (residual) tax

\footnotetext{
${ }^{20}$ Romer and Romer (2010) study the effect of a tax shock on the US GDP regressing the GDP on the contemporaneous value and 12 lags of their tax measure. Favero and Giavazzi (2012) add to the Romer and Romer (2010) specification some fiscal variables. They show that the truncated moving average representation of Romer and Romer (2010) shocks gives biased estimates of the output reaction because of correlation between the Romer and Romer (2010) shocks and distant lags of output and taxation. Because of that, they identify the shock via the contemporaneous value of the Romer and Romer (2010) shock (exogenous term) and treat it as the structural shock of one of the variables included in the VAR (revenues).

${ }^{21}$ Notice that correlation between the $\epsilon_{t}^{\text {Cloyne }}$ and the lagged values of tax revenues, included in vector $y_{t}$, is low and range between 0.02 and 0.05 .
} 
shock measure is 0.94 . We plug such residual in equation (1) and (3) instead of $\epsilon_{t}^{\text {Cloyne }}$, and we estimate them. Figure 7 plots the Cloyne tax measure (in our notation $\epsilon_{t}^{\text {Cloyne }}$ ) versus the alternative measures of tax shock identified by the residual of the above exercise, whereas figure 8 and table 4 report the IRFs and tax multipliers, respectively, from this exercise. The results are in line with the ones obtained from our baseline model.

The Cloyne's measure used to identify tax shocks includes, among the subcategories, the tax shocks driven by "deficit consolidation" (DC, henceforth) motivations. As pointed out by Cloyne (2013), the "DC" subcategory is different from the Romer and Romer (2010) one. In Romer and Romer (2010), the "DC" category is treaded as exogenous because it reflects past shocks, not related to macroeconomic conditions. For instance, it captures an increase in taxes to reduce an inherited deficit to long-run economic reasons. Conversely, Cloyne (2013) notes that in the UK part of tax changes due to fiscal consolidation is related to current macroeconomic conditions (endogenous). For that reason, the "DC" in Cloyne (2013) is more restrictive than in Romer and Romer (2010) one and, it includes only 12 observations. Once again, since tax shock is constructed on the base of policymakers' intentions, we verify the robustness of our results excluding from the $\epsilon^{\text {Cloyne }}$ the DC subcategory. Figure 8 and table 4 include the IRFs and tax multipliers from the above exercise showing that our baseline results, both in the linear and nonlinear specification, are not affected.

Alternative specification. Francis and Ramey (2009) and Owyang, Ramey, and Zubairy (2013) highlight the importance of including a quadratic trend in the US post-WWII period because of the slow-moving demographics. We address this issue for the UK replacing the linear time trend in equation (1) and (3) with the quadratic one. The results from this exercise is reported in figure 8 and table 4. Furthermore, to control for monetary policy actions we add to the control vector $y_{t}$ of equation (1) and (3) the policy rate and the inflation. ${ }^{22}$ Figure 9 and table 4 show that adding other variables to our baseline specification, both in the linear and nonlinear specification, does not affect our results.

Alternative values of the smoothness parameter. We calibrate the smoothness parameter $\gamma$ to match the frequencies of the UK recessions obtained via the $\mathrm{BBQ}$ algorithm (see Appendix $\mathrm{B}$ ), in our sample $F\left(z_{t}\right) \geq 0.85 \approx 0.15$. According to our metric, the UK economy spends $15 \%$ in recessions. To check the sensitivity of our results to the alternative calibrations of the smoothness

${ }^{22}$ The inflation rate is the annualized Retail Price Index, since the Consumer Price Index is not available from 1955 . 
parameter, we (re)calibrate $\gamma$ to include in our sample a number of recessions ranging from $10 \%$ to $20 \%$. The lower bound is set by the minimum amount of observations each regime should contain (Hansen, 1999). Figure 8 and table 4 show that our results are robust to alternative calibrations of $\gamma$ parameters.

Alternative indicators of states. In our baseline specification, we discriminate between recessions and expansions via the standardized backward-looking moving average over 2 quarters of the real GDP growth rate. To verify the robustness of our results using alternative indicators of the economic cycle, we run equation (3) plugging in $z_{t-i}$ the standardized deviation of: a) the growth rate (moving average over 2 quarters) of the output from the HP-filtered trend; b) change in the unemployment rate from the HP-filtered trend. To avoid smoothing out deep recessions and strong expansions, we use a large value of the smoothing parameter in the filter $(\lambda=10,000,000) .^{23}$

Figure 9 plot the IRFs of GDP, whereas table 4 reports the output multipliers from the above exercises. The results are qualitatively in line with our baseline results.

Controlling for anticipation and monetary policy regimes. To proxy the exogenous tax changes, we rely on the narrative measure constructed by Cloyne (2013) in which tax changes are aggregated on the base of the implementation date. In other words, it means agents react to tax changes when they are implemented and not before. However, the implementation may occur later than the announcement and agents may react to tax changes before the implementation. As highlighted by Cloyne (2013), the majority of tax changes in the UK are announced and implemented on the same quarter. However, to address the anticipation issue we proxy tax changes relying on the measure proposed by Cloyne (2013) that includes only tax changes implemented within 90 days of the announcement date. Moreover, the effects of tax change may depend on different monetary regime regimes. In 1979 the incoming conservative Government committed to reduce inflation. To this aim, the monetary policy was important.

To address the two above issues, we estimate a "tax change surprise" focusing on a sample size spanning from 1979:II to 2009:IV. Figure 9 yields similar results to our baseline.

Heteroskedasticity and autocorrelation. The Jordà method regresses the dependent variable at horizon $\mathrm{t}+\mathrm{h}$ on the shock in period $\mathrm{t}$. To overcome

${ }^{23}$ Our results are robust using a smoothing weight equal to 1,000,000,000 as in Auerbach and Gorodnichenko (2017). Results not shown here for the sake of brevity, but available upon request. 
the heteroskedasticity due to the successive leading of the dependent variable, we constructed the confidence intervals relying on the block bootstrap. However, we address the potential concerns of heteroskedasticity computing the standard errors for the impulse responses via the heteroskedasticity and autocorrelation (HAC) consistent estimator (Newey and West, 1987). Figure 10 plots the IRFs to a tax shock corresponding equal to $1 \%$ of GDP from the above exercise for GDP and its components (private consumption, investments, exports, imports, government consumption). All estimated responses are reported within plus and minus 1-standard error bands, which is based on heteroskedasticity and autocorrelation consistent (HAC) standard errors (see Newey and West, 1987). Our results are robust to the above exercise.

Overall, our results are robust to alternative specifications calling for a tailored used of the fiscal policy tool across the business cycle.

\section{Conclusions}

We study the nonlinear effects of an exogenous tax cut in the UK. The tax shock is identified by the measure proposed by Cloyne (2013). We model nonlinearity via the combination of local projection technique (Jordà, 2005) and smooth transition regressions (Granger and Teräsvirta, 1994). We find that the sign and the size of tax multipliers on GDP and its components are asymmetric across the business cycle. In recessions, a cut in taxes stimulates the economic activity and the GDP fluctuation is mainly driven by consumption. In expansions, output and consumption do not respond to a tax shock in the short-run. The reason can be found in the asymmetric reaction of government consumption across the business cycle. Since in expansions government consumption reacts negatively to tax shocks, it plays an important role in counteracting the (positive) effect of such shock on output and consumption.

Other studies in the literature, as Perotti (2005) and Cloyne (2013), find contrasting results: a positive tax shock has expansionary effect (albeit close to zero) in Perotti (2005), and contractionary one in Cloyne (2013). We reconcile these differences considering the state of the business cycles the economy is when exogenous tax change occurs. Linear predictions of tax multipliers lead to overestimate the benefits of decreasing taxes in expansions and underestimated the ones in expansions. The knowledge of how economic agents respond to tax shocks over the business cycle is crucial for designing fiscal policy and to evaluate 
the cost of fiscal measures.

The results documented in this paper lead to new research questions. First, we have seen that following a tax shock the reaction of imports and exports is different according to the state of economy. It would be interesting to study whether the UK tax shock has some (nonlinear) spillover effects on its trade partner countries. Second, we shed light that the state-dependent tax multipliers may differ among countries. It calls for future research to quantify the statedependent tax shock effects in countries different than the US. 


\section{References}

Afonso, A., J. Baxa, and M. Slavik (2018). "Fiscal Developments and Fiscal Stress: A Threshold VAR Analysis".

Alesina, A., C. Favero, and F. Giavazzi (2014). "The Output Effect of Fiscal Consolidations". Journal of International Economics forthcoming.

Auerbach, A.J. and Y. Gorodnichenko (2013a). "Fiscal Policy, Profits, and Investment". In: Alesina, A., and Giavazzi, F., (Eds.), Fiscal Policy after the Financial Crisis, Chicago, University of Chicago Press.

Auerbach, A.J. and Y. Gorodnichenko (2013b). "Output Spillovers from Fiscal Policy". American Economic Review 103(3), pp. 141-146.

Auerbach, A.J. and Y. Gorodnichenko (2012). "Measuring the Output Responses to Fiscal Policy". American Economic Journal: Economic Policy 4(2), pp. 127.

Auerbach, A.J. and Y. Gorodnichenko (2017). "Fiscal Multiplier in Japan".

Barro, B. J. and C. J. Redlick (2011). "Macroeconomic Effects from Government Purchases and Taxes". Quarterly Journal of Economics 126(1), pp. 51-102.

Baum, A., M. Poplawski-Ribeiro, and A. Weber (2012). "Fiscal Multipliers and the State of the Economy". International Monetary Fund Working Paper No. $12 / 286$.

Ben Zeev, N. and E. Pappa (2017). "Chronicle of a War Foretold: The Macroeconomic Effects of Anticipated Defense Spending Shocks". The Economic Journal 127(603).

Blanchard, O. and D. Leigh (2013). "Growth Forecast Errors and Fiscal Multipliers". American Economic Review 103(3), pp. 117-120.

Blanchard, O. and R. Perotti (2002). "An Empirical Characterization of the Dynamic Effects of Changes in Government Spending and Taxes on Output". Quarterly Journal of Economics 117(4), pp. 1329-1368.

Caggiano, G., E. Castelnuovo, V. Colombo, and G. Nodari (2015). "Estimating Fiscal Multipliers: News From a Nonlinear World". Economic Journal, forthcoming.

Caldara, D. and C. Kamps (2008). "What are the Effects of Fiscal Policy Shocks?" ECB WP 0877/ March.

Caldara, D. and C. Kamps (2017). "The Analytics of SVARs: A Unified Framework to Measure Fiscal Multipliers". Review of Economic Studies, Oxford University Press, 84(3), pp. 1015-1040. 
Cloyne, J. (2013). "Discretionary Tax Changes and the Macroeconomy: New Narrative Evidence from the United Kingdom". American Economic Review 103(4), pp. 1507-1528.

Demirel, U. D. (2016). "The short-term effects of tax changes-evidence for state dependence." Congressional Budget Office Working Paper 2016-03.

Devries, P., J. Guajardo, D. Leigh, and A. Pescatori (2011). "A New Action-based Dataset of Fiscal Consolidation". IMF WP/11/128.

Eskandari, R. (2019). "State Dependent Macroeconomic Effects of Tax Change". mimeo.

Favero, C. and F. Giavazzi (2012). "Measuring Tax Multipliers: The Narrative Method in Fiscal VARs". American Economic Journal: Economic Policy 4(2), pp. 69-94.

Francis, N. and V. A. Ramey (2009). "Measures of per capita hours and their implications for the technology-hours debate". Journal of Money, Credit and Banking 41(6), pp. 1071-1097.

Ghassibe, M. and F. Zanetti (2019). "State Dependence of Fiscal Multipliers: The Source of Fluctuations Matters". University of Oxford, mimeo.

Giorno, C., P. Richardson, D. Roseveare, and P. van den Noord (1995). "Potential Output, Output Gaps and Structural Budget Balances". OECD Economic Studies, No. 24, Paris.

Granger, C. W. J. and T. Teräsvirta (1994). "Modelling Nonlinear Economic Relationships". International Journal of Forecasting 10(1), pp. 169-171.

Guajardo, J., D. Leigh, and A. Pescatori (2014). "Expansionary Austerity: New International Evidence". Journal of the European Economic Association, 12(4), pp. 949-968.

Hall, R. E. (2009). "By How Much Does GDP Rise If the Government Buys More Output?" Brookings Papers on Economic Activity, Economic Studies Program, Brookings Institution, pp. 183-249.

Hansen, B. (1999). "Testing for Linearity". Journal of Economic Surveys 13(5), pp. $551-576$.

Harding, D. (2008). "Detecting and Forecasting Business Cycle Points". MPRA 33583.

Hayo, B. and M. Uhl (2014). "The Macroeconomic Effects of Legislated Tax Changes in Germany". Oxford Economic Papers 66(2), pp. 397-418.

Ilzetzki, E., E.G. Mendoza, and C.A. Végh (2013). "How big (small?) are fiscal multipliers?" Journal of Monetary Economics 60, pp. 239-254. 
Jordà, O. (2005). "Estimation and Inference of Impulse Responses by Local Projections". American Economic Review 95(1), pp. 161-182.

Kaplan, G. and G.L. Violante (2014). "A Model of the Consumption Response to Fiscal Stimulus Payments ". Econometrica 82(4), pp. 1199-1239.

Leduc, S. and D. Wilson (2012). "Roads to Prosperity or Bridges to Nowhere? Theory and Evidence on the Impact of Public Infrastructure Investment". NBER Macroeconomics Annual.

Lukkonen, R., P. Saikkonen, and T. Teräsvirta (1988). "Testing linearity against Smooth Transition Autoregressive models". Biometrika 75, pp. 491-499.

Mertens, K. and M. O. Ravn (2014). "A reconsiliation of SVAR and the Narrative Estimates of Tax Multipliers". Journal of Monetary Economics 68, S1-S19.

Mountford, A. and H. Uhlig (2009). "What are the Effects of Fiscal Policy Shocks?" Journal of Applied Econometrics 24(6), pp. 960-992.

Newey, W.K. and K.D. West (1987). "A simple, positive semi-definite, heteroskedasticity and autocorrelation consistent covariance matrix." Econometrica 55, pp. 703-708.

Owyang, M., V. A. Ramey, and S. Zubairy (2013). "Are Government Spending Multipliers Greater During Periods of Slack? Evidence from 20th Century Historical Data”. American Economic Review Papers and Proceedings 103(3), pp. 129-134.

Pereira, M. C. and L. Wemans (2015). "Output effects of a measure of tax shocks based on changes in legislation for Portugal". Review of Public Economics 215(4), pp. 27-62.

Perotti, R. (2005). "Estimating the Effects of Fiscal Policy in OECD Countries". CEPR Discussion Paper 4842.

Perotti, R. (2012). "The Effects of Tax Shocks on Output: Not So Large, But Not Small Either". American Economic Journal: Economic Policy 4(2), pp. 214237.

Plagborg-Møller, M. and C. K. Wolf (2019). "Local projections and vars estimated the same impulse responses ". Princeton University, mimeo.

Politis, D. and J. Romano (1992). "A circular block resampling procedure for stationary data". LePage R., Billiard L. (Eds.), Exploring the limits of bootstrap, Wiley and Sons, New York.

Ramey, V. A. (2011). "Identifying Government Spending Shocks: It's All in the Timing". Quarterly Journal of Economics 126(1), pp. 1-50. 
Ramey, V. A. and M. D. Shapiro (1998). "Costly capital reallocation and the effects of government spending". Carnegie-Rochester Conference Series on Public Policy 48, pp. 145-194.

Ramey, V. A. and S. Zubairy (2018). "Government Spending Multipliers in Good Times and in Bad: Evidence from U.S. Historical Data". Journal of Political Economy 126(2), pp. 850-901.

Ramey, V.A. (2019). "Ten Years after the Financial Crisis: What Have We Learned from the Renaissance in Fiscal Research?" Journal of Economic Prospective 33(2), pp. 89-114.

Romer, C. and D. Romer (2010). "The Macroeconomic Effects of Tax Changes: Estimates Based on a New Measure of Fiscal Shocks". American Economic Review 100, pp. 763-801.

Sims, E. and J. Wolff (2018). "The state-dependent effects of tax shocks". European Economic Review 107, pp. 57-85.

Tagkalakis, A. (2008). "The Effects of Fiscal Policy on Consumption in Recessions and Expansions". Journal of Public Economics 92(5-6), pp. 1486-1508.

Teräsvirta, T. (1988). "Modelling Economic Relationships with Smooth Transition Regressions". In: Giles, D., Ullah, A., C. (Eds.), Handbook of Applied Economic Statistics, Dekker.

van den Noord, P. (2002). "Automatic Stabilizers in the 1990s and Beyond". Buti, M., von Hagen, J., Martinez-Mongay, C. (Eds.), The Behavior of Fiscal Authorities: Stabilization, Growth and Institutions, Palgrave. 
Table 1: Data Sources

\begin{tabular}{lll}
\hline \hline Series & Description & Sources \\
\hline & & \\
GDP & Real GDP & ONS \\
Nominal GDP & GDP in current prices & ONS \\
Consumption & Final household consumption expenditure & ONS \\
Investment & Gross fixed capital formation & ONS \\
Imports & Trade in goods and services: Total imports & ONS \\
Exports & Trade in goods and services: Total exports & ONS \\
Population & UK total population & Eurostat \\
Inflation & Change in Retail Prices Index & ONS \\
Interest rate & Official Bank rate & Bank of England \\
Government consumption & Government consumption of goods and services & ONS \\
Tax revenues & Total tax and NI receipts & ONS \\
Cloyne's Tax Shocks & Exogenous tax changes (Cloyne, 2013) & AER's website \\
\hline \hline
\end{tabular}




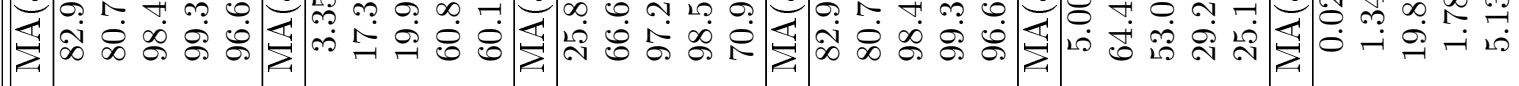

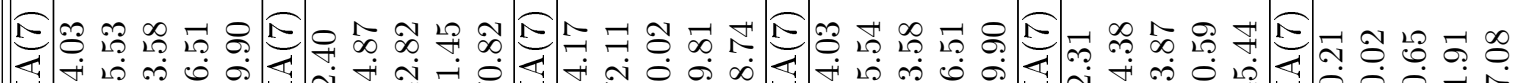

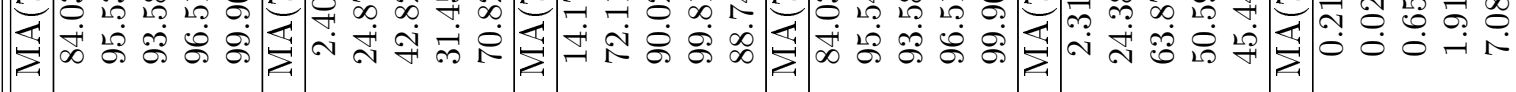

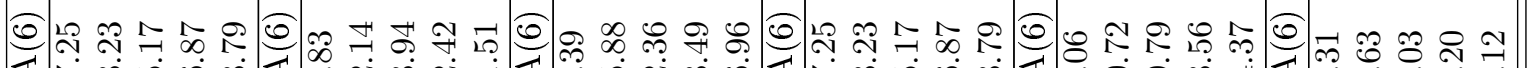

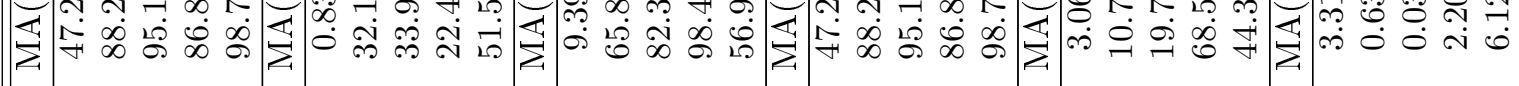

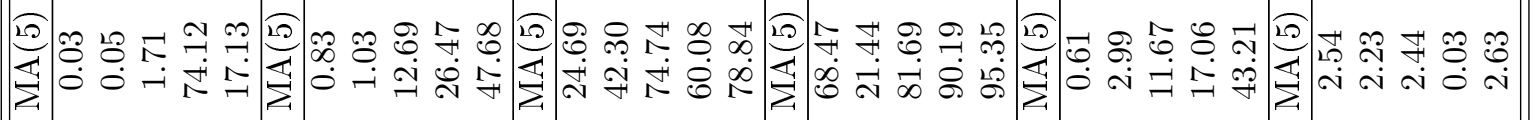

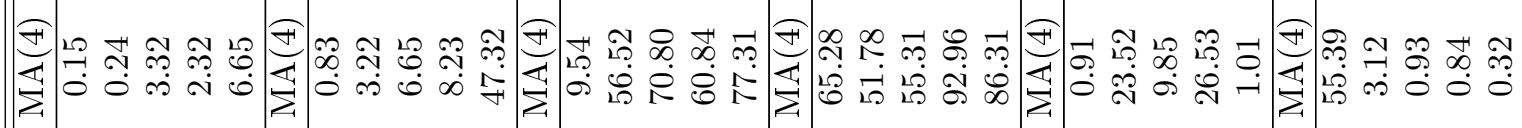

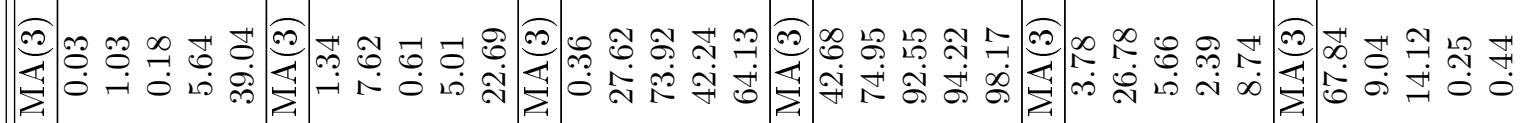

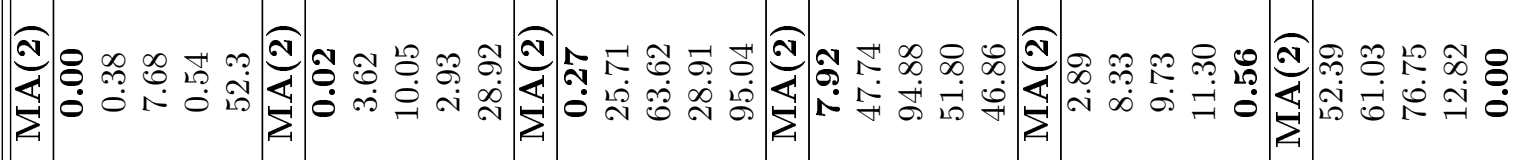

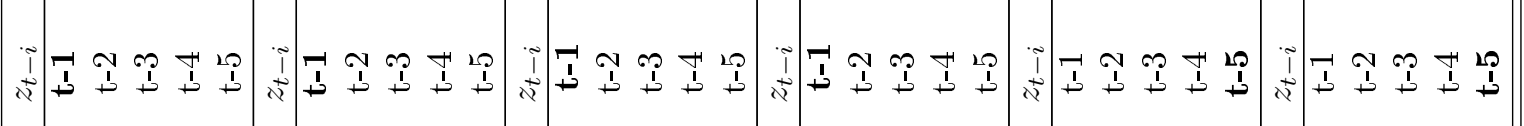

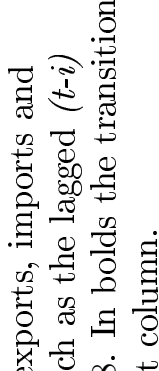

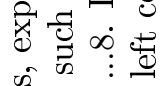

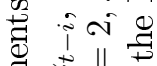

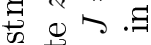
菏 $U$ $\exists$ 范 ฮี ฮี สี 药 की ¿ 莡: 년

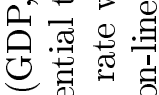

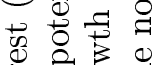
包苟

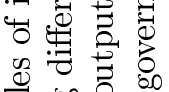
की 000

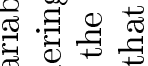
ग प्र प유용 可焉

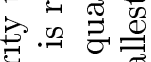
ซ్ ఫ 总苛焉 จ s. 赵范

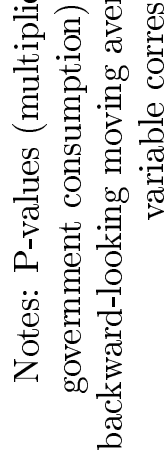


Table 3: Output Tax Multipliers (baseline)

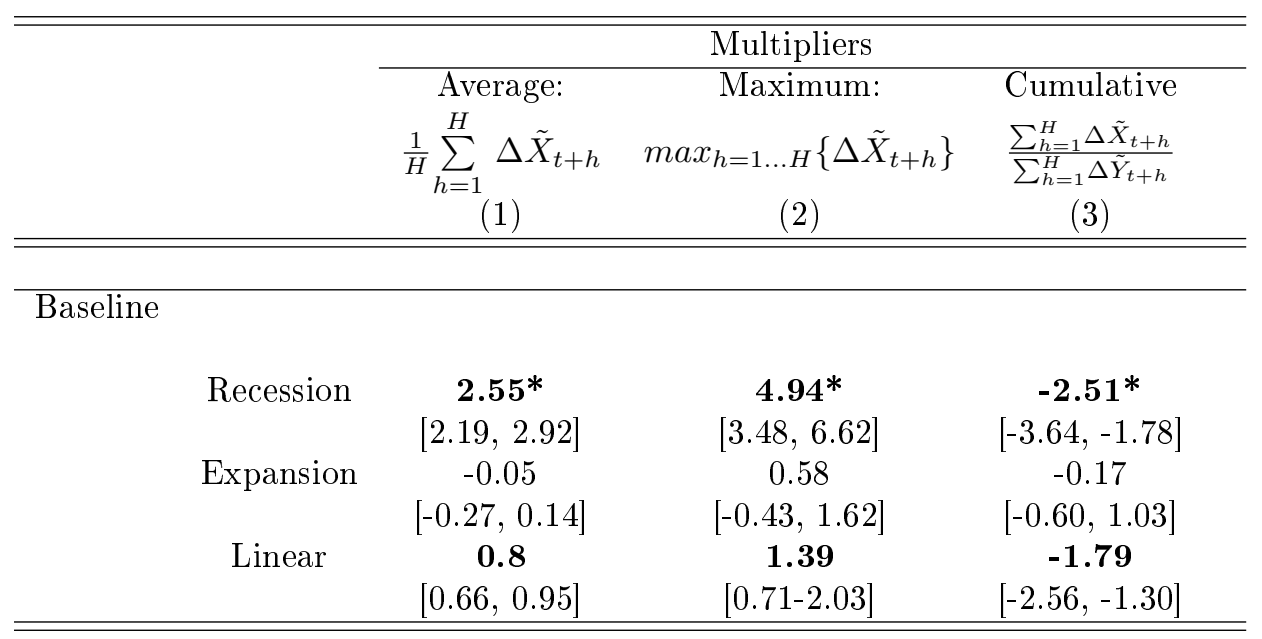

Output Tax Multipliers. Notes: the table shows the multipliers on output to a tax cut corresponding to $1 \%$ of GDP. We report the average, the maximum and the cumulative output tax multipliers, columns (1) to (3) respectively. The multipliers are calculated over twelve quarters and in recessions, expansions, and in the linear case. Bold numbers mean that the coefficients are statistically significant at $68 \%$ confidence intervals. Asterisks mean that the coefficients are statistically significant different across regimes (recessions versus expansions) at the $68 \%$ level. 
Table 4: Robustness checks: Output Tax Multipliers

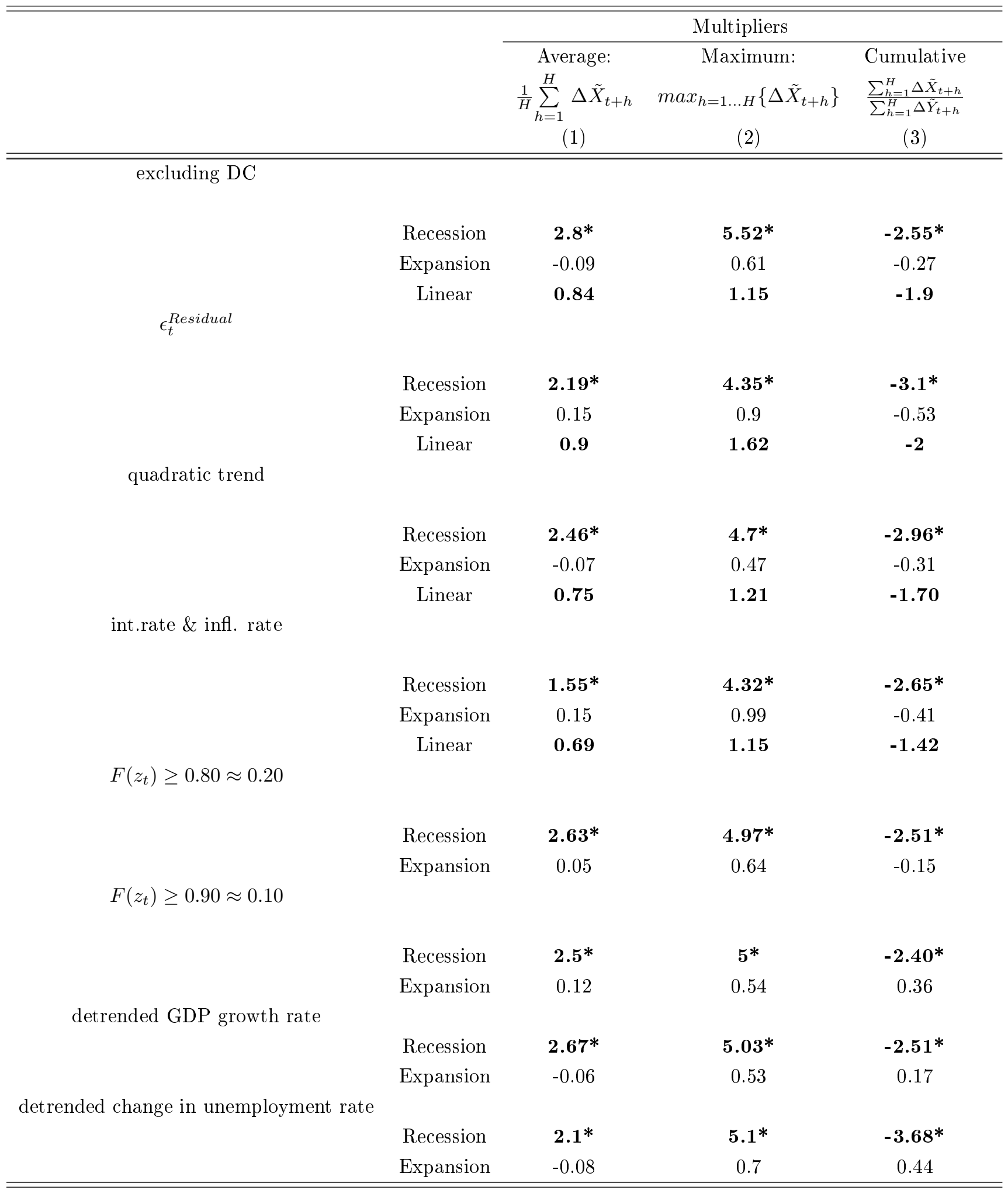

Notes: The table shows the multipliers on output to a tax cut corresponding to $1 \%$ of GDP under alternative specifications. We report the average, the maximum and the cumula- 
tive output tax multipliers, columns (1) to (3) respectively. The multipliers are calculated over twelve quarters and in recessions, expansions, and in the linear case. Bold numbers mean that the coefficients are statistically significant based on the $16^{\text {th }}$ and $84^{\text {th }}$ percentiles of empirical distribution. Asterisks mean that the coefficients are statistically significant different in recessions versus expansions (at the $16^{t h}-84^{\text {th }}$ percentile range). Each block refers to an alternative specification of our baseline. From the top block to the bottom one: (i) excluding the deficit consolidation (DC) component from the overall tax shock measure; (ii) identification of tax shock via the "residual tax shock"; (iii) (re-)estimate the model including a quadratic trend instead of the linear one; (vi) add to the control vector the monetary policy and inflation rate; (v) (re)calibrate the probability of being in recessions equal to $10 \%$ and (vi) to $20 \%$; (vii) rely on the growth rate (moving average over 2 quarters) of the output from the HP-filtered trend as indicator of the business cycle; (viii) rely on the change in the unemployment rate from the HP-filtered trend as indicator of the business cycle. 
Figure 1: Tax shock vs Business cycle

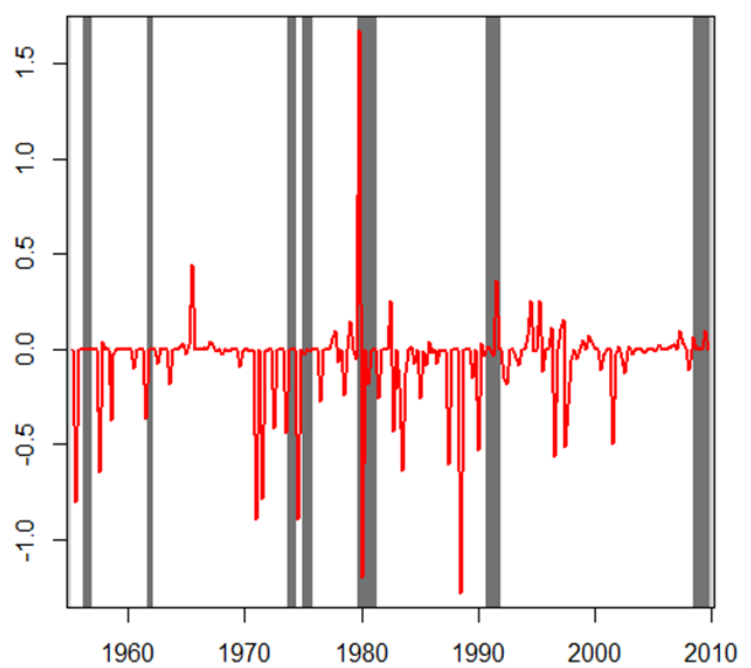

Notes: The shaded area indicate the UK recessionary phases (1955:I-2009:IV) identified by applying the BBQ algorithm, whereas the red lines refers to the tax shock measure of Cloyne (2013).

Figure 2: Transition variable versus Business Cycle Dates

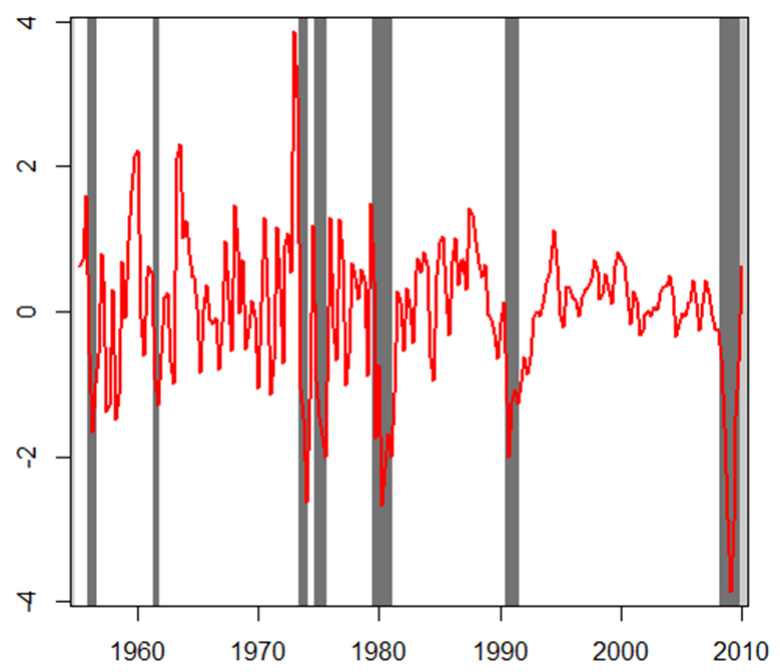

Notes: the transition variable is the standardized backward-looking moving average constructed with two realizations of the quarter-on-quarter real GDP growth rate. Shaded area refers to the recessionary phase identified applying the BBQ algorithm (Harding and Pagan, 2002) 
Figure 3: Probability of being in a recessionary phase

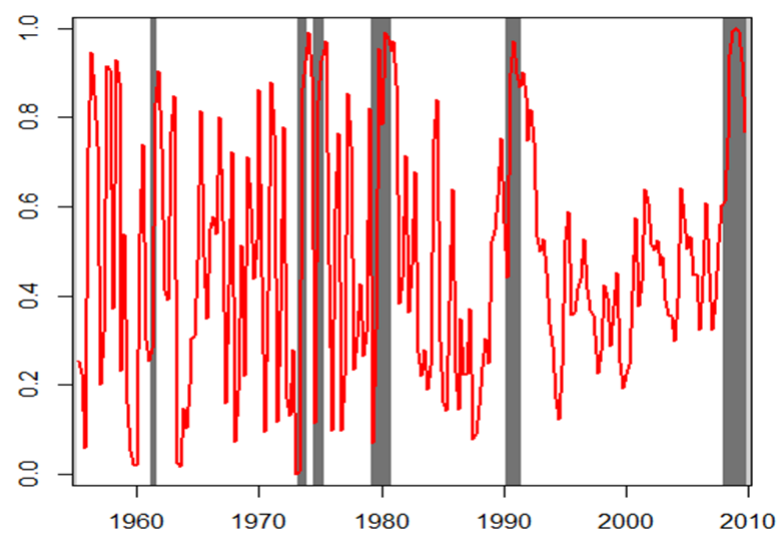

Notes: $F\left(z_{t}\right)$ computed according to the logistic function presented in the text. The transition variable is the standardized backward-looking moving average constructed with two realizations of the quarter-on-quarter real GDP growth rate. The value of the slope parameter is 1.7 . 
Figure 4: Response of GDP to 1 percent of GDP cut in taxes
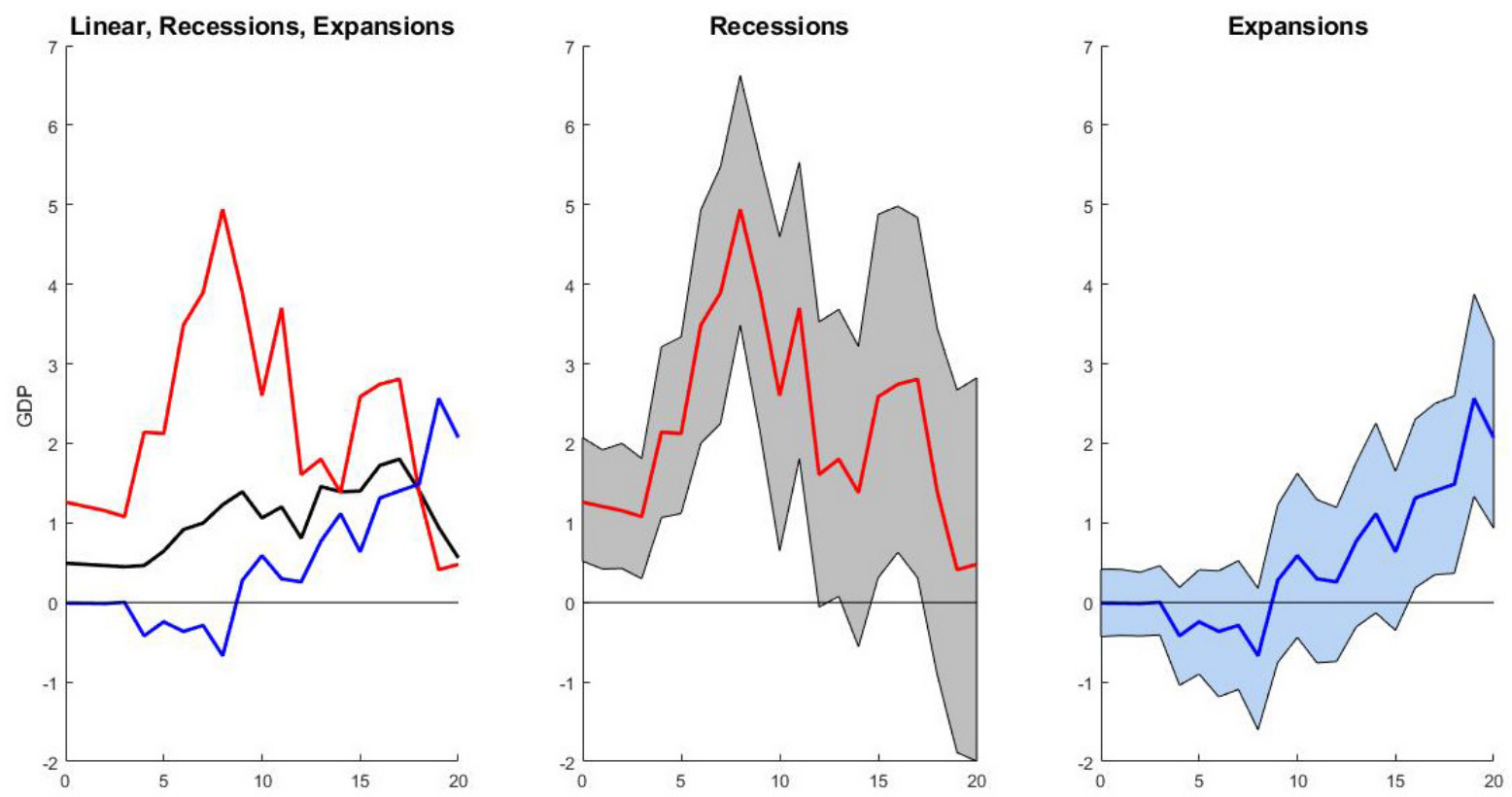

Notes: Figure plots the impulse responses of output to a cut of taxes equal to $1 \%$ of GDP. The blue lines denote the IRFs in expansions, the red lines the ones in recessions, whereas the black line the reaction of output estimated via the linear model. The first column of the figure reports the linear and the state-dependent responses. The second and third column report the IRFs for the recessionary and expansionary case, respectively, and the $16^{\text {th }}$ and $84^{\text {th }}$ percentiles of the distribution of the responses at each horizon. The impulse responses are expressed as percent change of GDP. Horizontal axes represent quarters. 
Figure 5: Response of GDP components to 1 percent of GDP cut in taxes

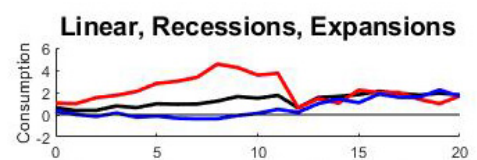

Linear, Recessions, Expansions
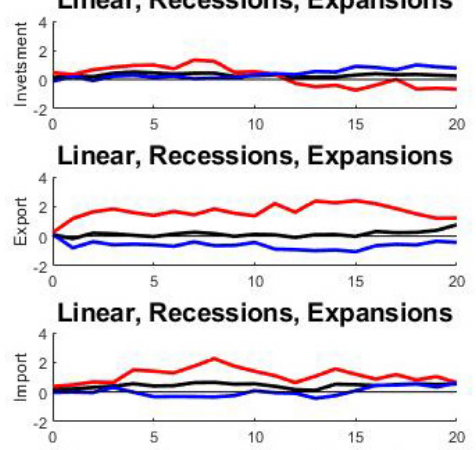

Linear, Recessions, Expansions

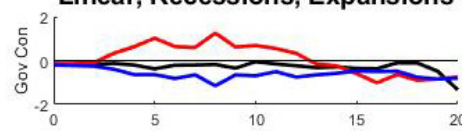

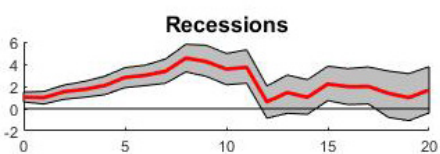
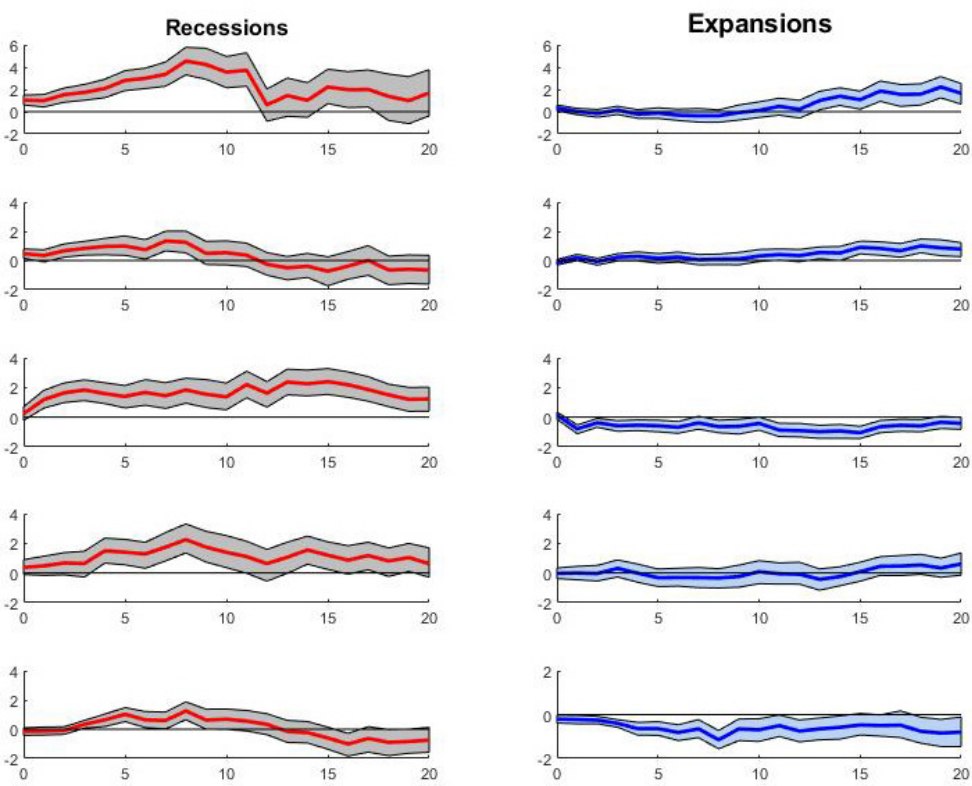
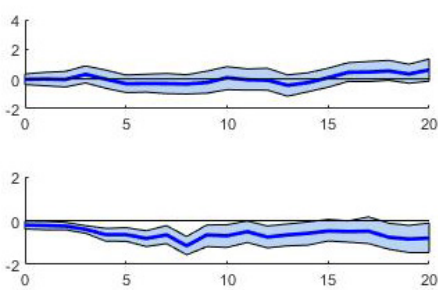

Notes: Figure plots the impulse responses of consumption (row I), investment (row II), exports (row III), imports (row IV), and government consumption (row V) to a cut of taxes equal to $1 \%$ of GDP. The blue lines denote the IRFs in expansions, the red lines the ones in recessions, whereas the black lines the reaction of output estimated via the linear model. The first column of the figure reports the linear and the state-dependent responses. The second and third column report the IRFs for the recessionary and expansionary case, respectively, and the $16^{\text {th }}$ and $84^{\text {th }}$ percentiles of the distribution of the responses at each horizon. The impulse responses are expressed as percent change of GDP. Horizontal axes represent quarters. 
Figure 6: Differences in Impulse Responses of GDP and its components to a tax cut
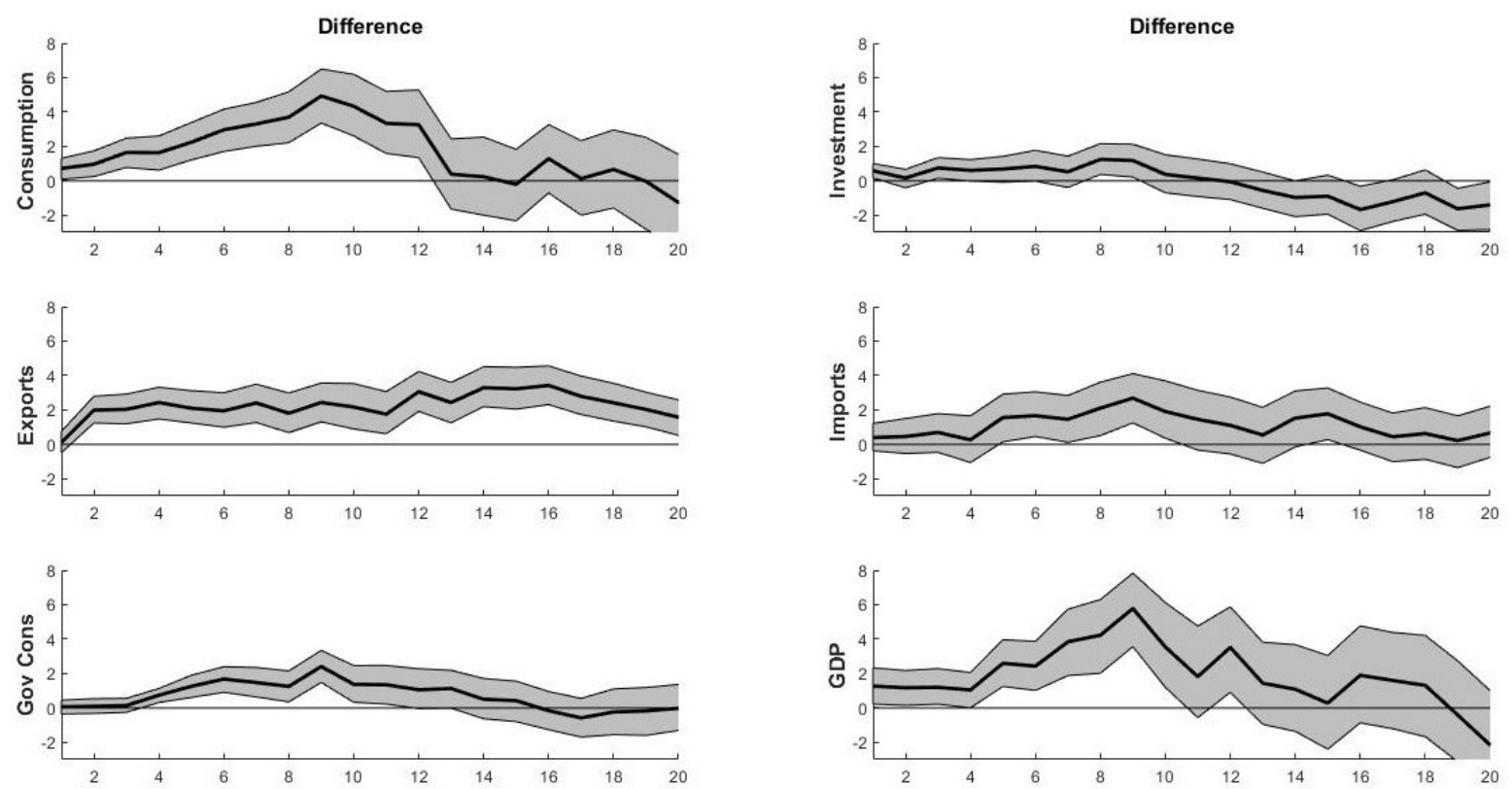

Notes: Figure plots the median realizations of the differences between impulse responses in recessions and expansions to 1 percent of GDP cut in taxes for consumption, investment, exports, imports, government consumption and GDP. Shaded bands refer to the $16^{\text {th }}$ and $84^{\text {th }}$ percentiles of the distribution of the difference at each horizon. (shaded bands). Horizontal axes represent quarters. 
Figure 7: Cloyne shocks and its exogeneity

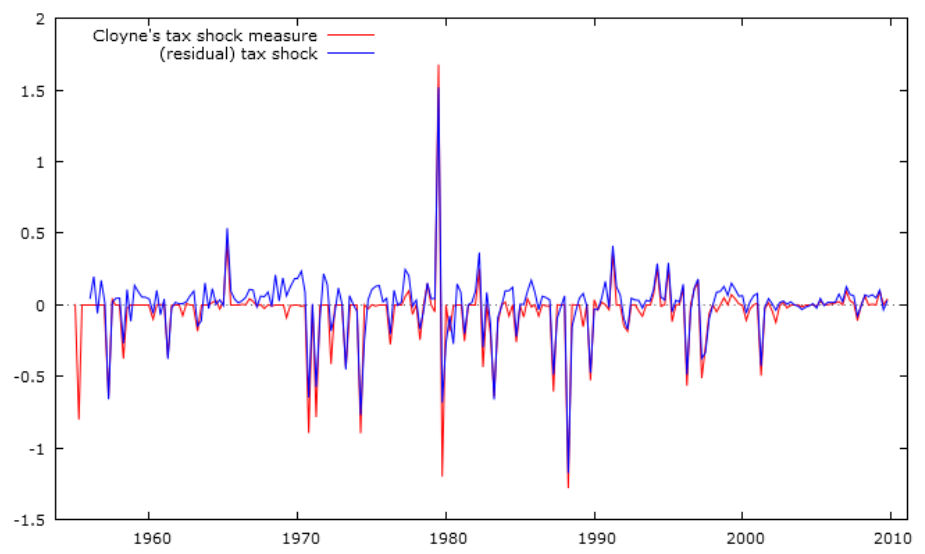

Notes: Figure plots the tax shock series constructed by Cloyne (2013), in our notation $\epsilon_{t}^{\text {Cloyne }}$, versus the (residual) tax shock series obtained regressing the $\epsilon_{t}^{\text {Cloyne }}$ on its own four lags and four lags of the log real GDP, revenues and government consumption. 
Figure 8: Response of GDP to 1 percent of GDP cut in taxes (alternative specifications)
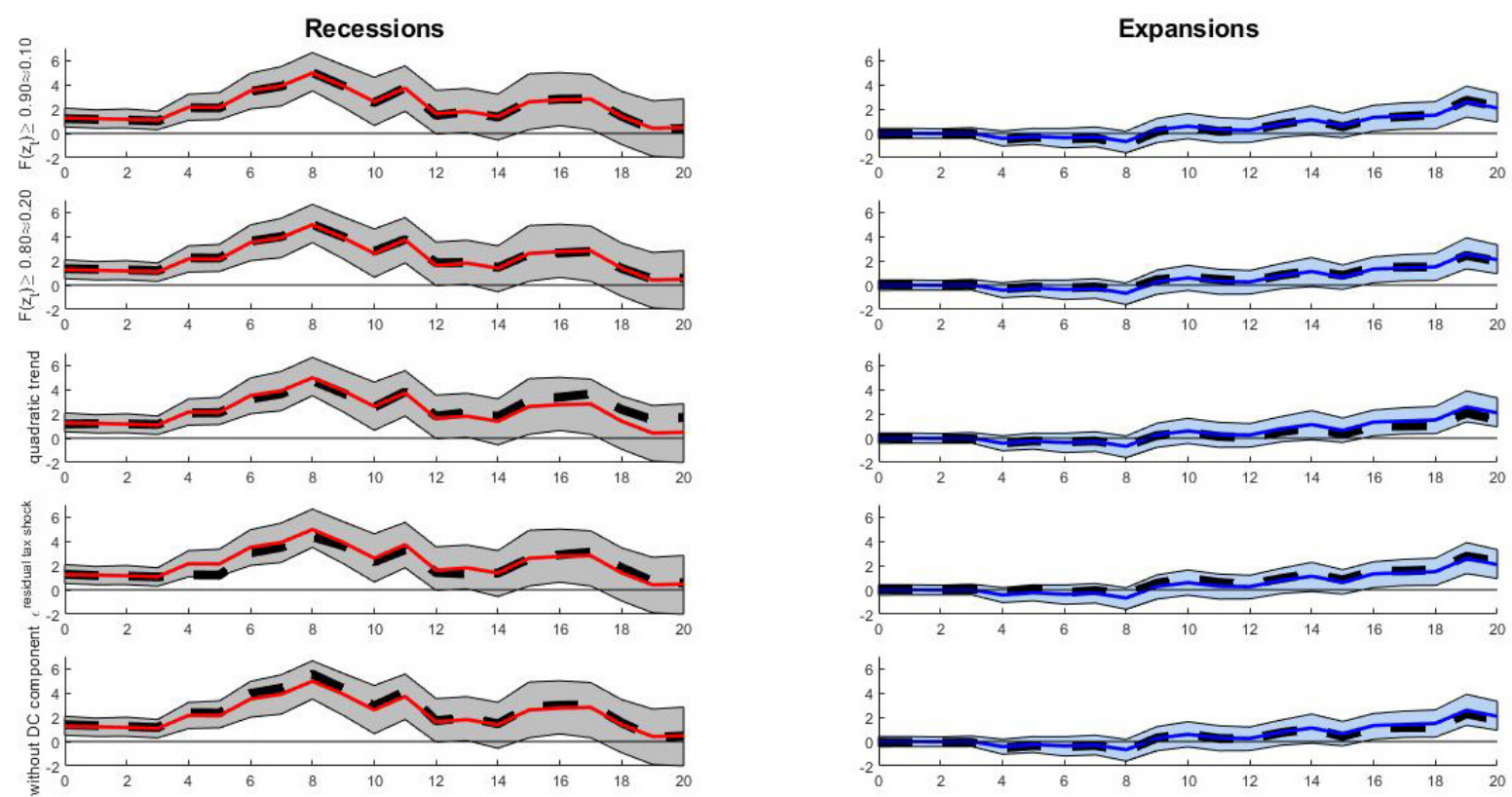

Notes: Figure plots the state-dependent impulse responses of output to a cut of taxes equal to $1 \%$ of GDP under alternative specifications. The column on the left reports the IRFs for the recessionary case, whereas the column on the right plots the IRFs for the expansionary one. Each row refers to an alternative specification of our baseline. For each specification, the figure shows the IRFs from the baseline specification and the $16^{\text {th }}$ and $84^{\text {th }}$ percentiles of the distribution (shaded bands) against the IRFs from the alternative specification (black dotted lines). From the top to the bottom: (i) (re)calibrate the probability of being in recessions equal to $10 \%$ and (ii) to $20 \%$; (iii) (re-)estimate the model including a quadratic trend instead of the linear one; (iv) identification of tax shock via the "residual tax shock"; (v) excluding the deficit consolidation (DC) component from the overall tax shock measure. 
Figure 9: Response of GDP to 1 percent of GDP cut in taxes (alternative specifications, cont'd)
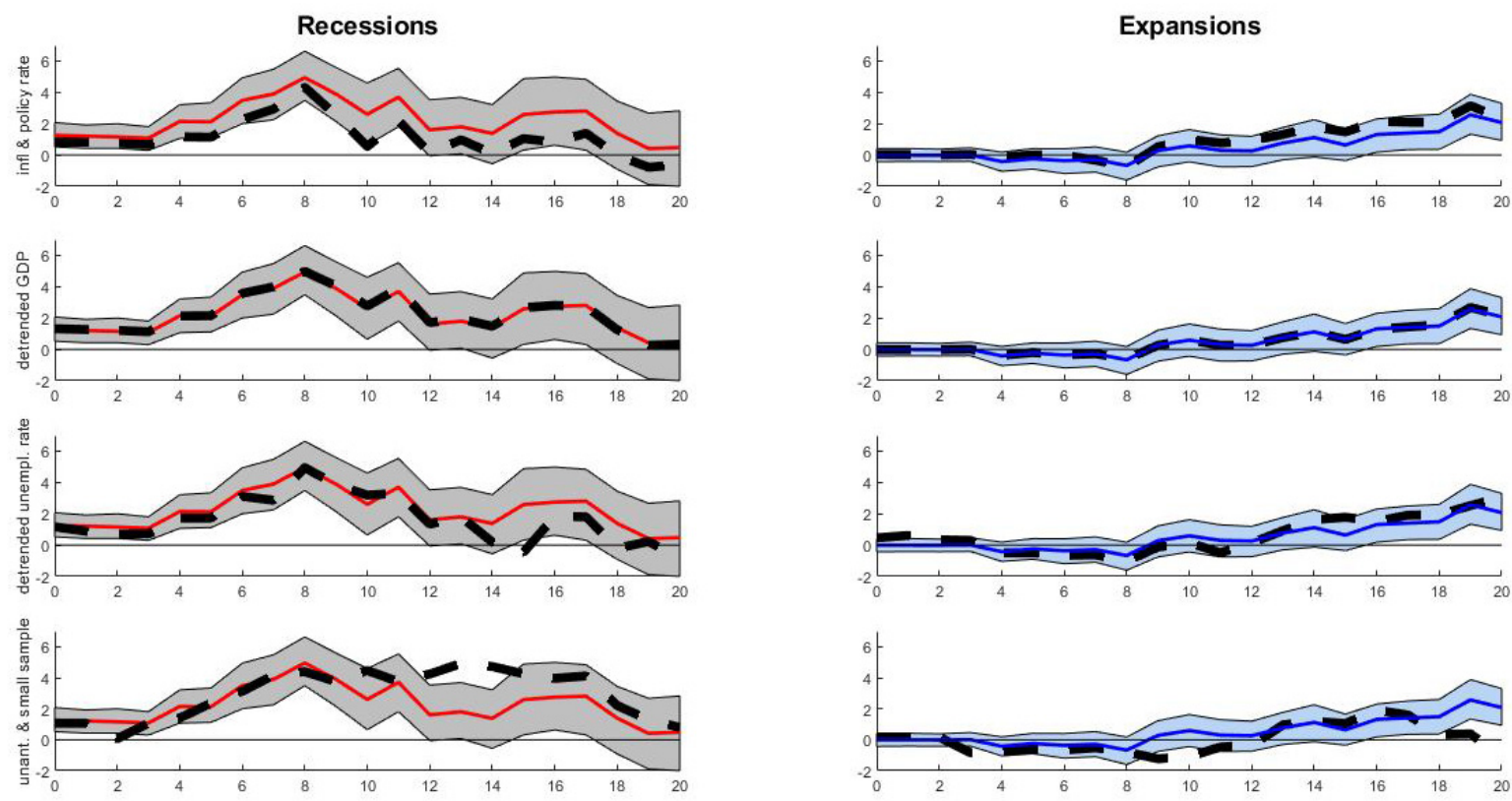

Notes: Figure plots the state-dependent impulse responses of output to a cut of taxes equal to $1 \%$ of GDP under alternative specifications. The column on the left reports the IRFs for the recessionary case, whereas the column on the right plots the IRFs for the expansionary one. Each row refers to an alternative specification of our baseline. For each specification, the figure shows the IRFs from the baseline specification and the $16^{t h}$ and $84^{t h}$ percentiles of the distribution (shaded bands) against the IRFs from the alternative specification (black dotted lines). From the top to the bottom: (i) add to the control vector the monetary policy and inflation rate; (ii) rely on the growth rate (moving average over 2 quarters) of the output from the HP-filtered trend as indicator of the business cycle; (iii) rely on the change in the unemployment rate from the HP-filtered trend as indicator of the business cycle; (iv) controlling for anticipation and monetary policy regimes. 
Figure 10: Response of GDP and its components to 1 percent of GDP cut in taxes (HAC standard errors)
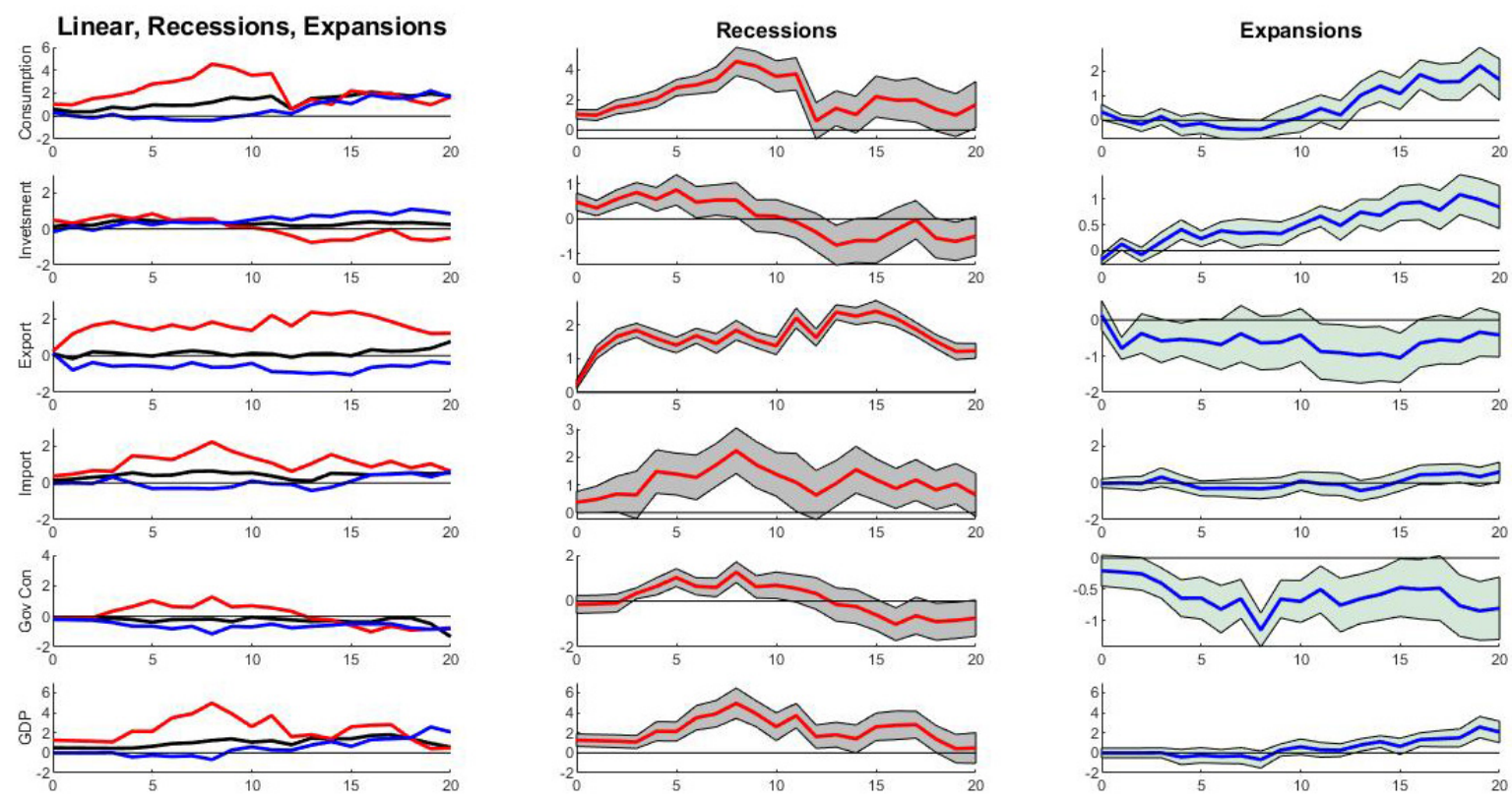

Notes: The figure plots the impulse responses of private consumption, investments, exports, imports, government consumption and output to a tax shock corresponding equal to $1 \%$ of GDP. All estimated responses are reported within plus and minus 1-standard error bands, which is based on heteroskedasticity and autocorrelation consistent (HAC) standard errors (see Newey and West, 1987). 


\section{A Appendix}

\section{Output Elasticity of Revenues and conversion factors of elasticity into multiplier: Do they matter for the Tax Multiplier?}

The main challenge in estimating the tax multiplier is to disentangle a tax change due to a discretionary fiscal policy from a nondiscretionary component, e.g. the change in taxes due to a change in output. Two methods have been proposed in the literature. The first one relies on the SVAR model and based mainly on the identification assumption scheme pioneered by Blanchard and Perotti (2002). The second one identifies an exogenous tax change using a narrative method (Romer and Romer, 2010; Mertens and Ravn, 2014; Cloyne, 2013). Despite several studies investigating tax multipliers, there is not a shared view. Perotti (2005), identifying a tax shock via coefficient restrictions, finds that following a tax shock the UK GDP decrease. Cloyne (2013) identify a tax shock through the narrative approach and finds that a tax cut stimulates the economy. In general, the size and duration of a tax shock vary across studies and the estimated tax multiplier via a SVAR model tends to be lower than the narrative approach.

Caldara and Kamps (2008) show that contrasting US fiscal multiplier estimations are likely due to different assumptions on the size of the elasticity of tax revenues to GDP. The first question addressed in this section is whether the UK output tax multiplier is "output elasticity of taxes dependent". To do that we employ in very basic (linear) SVARs two measures of the UK automatic stabilizer proposed in the literature by Perotti (2005) and Cloyne (2013).

Consider a simple three-variate VAR as in Blanchard and Perotti (2002) ${ }^{24}$ of the form:

$$
X_{t}=C(L) X_{t-1}+u_{t} \quad t=1, \ldots, T
$$

where $X_{t}$ includes four lags of the log real per capita government consumption, tax revenues and GDP and $u_{t}$ is a three-dimensional vector of residuals. Equation (A.1) includes also a constant and a linear time trend. Following the approach

\footnotetext{
${ }^{24}$ Notice that Perotti (2005) estimates for the UK a five-variable VAR. Caldara and Kamps (2008) show that different results in the literature about the US fiscal multipliers are not due to difference in the specification of the reduced-form models but to the different identification strategies. We stress that the exercise provided in this section is not aimed at choosing the best specification for our analysis but to understand whether the Caldara and Kamps' result is valid also for the UK economy. Hence, we estimate a more parsimonious VAR, as in Blanchard and Perotti (2002).
} 
proposed by Perotti (2005), the reduced form innovations of vector $u_{t}$ is expressed as a linear combination of the structural shocks such that:

$$
\begin{aligned}
& u_{t}^{G}=\alpha_{Y}^{G} u_{t}^{Y}+\beta_{T}^{G} \epsilon_{t}^{T}+\epsilon_{t}^{G} \\
& u_{t}^{T}=\alpha_{Y}^{T} u_{t}^{Y}+\beta_{G}^{T} \epsilon_{t}^{G}+\epsilon_{t}^{T} \\
& u_{t}^{Y}=\alpha_{G}^{Y} u_{t}^{G}+\alpha_{T}^{Y} u_{t}^{T}+\epsilon_{t}^{Y}
\end{aligned}
$$

Since the aim is estimating the effect of a tax shock $\epsilon_{t}^{T}$ on the GDP, let us focus on equation (A.3). It states that unexpected movement in taxes at time $t$ may be due to output innovations $\left(u_{t}^{Y}\right)$, structural shocks to government consumption $\left(\epsilon_{t}^{G}\right)$ or to taxes $\left(\epsilon_{t}^{T}\right)$. Hence, the coefficients $\alpha_{j}^{i}$ capture the elasticity of variable $i$ to the variable $j$, while coefficients $\beta_{j}^{i}$ capture possible link between structural shocks to fiscal variable which may arise whether, for instance, government consumption instantaneously responds to revenues change with government consumption adjustment. The identification of a tax shock is based on the $A u_{t}=\mathrm{B} \epsilon_{t}$ scheme and on some restrictions on the matrix $\mathrm{A}$ and $\mathrm{B}$ to map from innovations $u_{t}^{T}$ to the structural shocks $\epsilon_{t}^{T}$. Expressed in matrix notation:

$$
\left[\begin{array}{ccc}
1 & 0 & -\alpha_{Y}^{G} \\
0 & 1 & -\alpha_{Y}^{T} \\
-\alpha_{Y}^{G} & -\alpha_{T}^{Y} & 1
\end{array}\right]\left[\begin{array}{c}
u_{t}^{G} \\
u_{t}^{T} \\
u_{t}^{Y}
\end{array}\right]=\left[\begin{array}{ccc}
\sigma^{G} & \beta_{T}^{G} & 0 \\
\beta_{G}^{T} & \sigma^{T} & 0 \\
0 & 0 & \sigma^{Y}
\end{array}\right]\left[\begin{array}{c}
\epsilon_{t}^{G} \\
\epsilon_{t}^{T} \\
\epsilon_{t}^{Y}
\end{array}\right]
$$

The identification of fiscal shock in Blanchard and Perotti (2002) relies on some assumptions about the reaction lags and the structural elasticity. Suppose that there is a negative output shock. To offset such shock a fiscal policy action should be planned, approved by the House of Commons and then implemented. It should take more than one quarter to apply a discretionary fiscal policy. With quarterly data, the contemporaneous response of the government spending to an output shock can be set to zero. Also, the implementation lags imply that coefficient $\alpha_{Y}^{T}$ captures only the automatic elasticity of the tax revenues to GDP due to a fluctuation in the tax base. Thus, the cyclically-adjusted tax innovation, $u_{t}^{C A T}$, is given by the difference between the tax innovation $\left(u_{t}^{T}\right)$ and the output elasticity of revenues $\left(\alpha_{Y}^{T}\right)$. Notice that the restricted value of the coefficient $\alpha_{Y}^{T}$ is obtained by an out-of-model information. ${ }^{25}$ Hence, the cyclical adjusted

\footnotetext{
${ }^{25}$ Perotti (2005) calibrates the value of the automatic stabilizer for the UK economy through the OECD method and assumptions proposed by Giorno, Richardson, Roseveare, and van den Noord (1995) and van den Noord (2002). The output elasticity of output is calibrated
} 
tax innovation derives from an instrumental variable estimation. The structural shock $\epsilon_{t}^{T}$ is recovered imposing a recursive order on matrix $\mathrm{A}$, on which we assume that tax shock "comes first" than government spending one. Thus, we set $\beta_{G}^{T}=0 .{ }^{26}$

Estimated impulse response functions obtained via the estimation of (A.5) allow us to address a second problem, the ex post conversion factor's, raised by Owyang, Ramey, and Zubairy (2013). It is related to the estimation of fiscal multipliers. In general, it is common practice in the fiscal multiplier literature to run SVARs using log-transformed variables, and then to convert estimated elasticities into multipliers via (ex post) conversion factors, e.g. the average of the ratio GDP/(fiscal variable). However, Owyang, Ramey, and Zubairy (2013) highlight that different sample size may rend different conversion factor values, which may lead to biased fiscal multiplier estimates.

Output Elasticity of Revenues and conversion factors of elasticity into multiplier: Do they matter for the Tax Multiplier? This paper address the two problems through simple exercises. We consider two sample sizes spanning one from 1963:I to 2001:II, and the other one from 1955:I to 2009:IV. For each sample size, we estimate two SVARs including the quarterly log of the real government consumption, tax revenues, and GDP, ${ }^{27}$ and imposing the implementation lag coefficient restrictions discussed above. Notice that for each sample size two alternative coefficient restrictions of output elasticity of taxes $\left(\alpha_{Y}^{T}\right)$ are set. On the one hand, we set $\alpha_{Y}^{T}=0.76$ as in Perotti (2005). On the other hand, we fix $\alpha_{Y}^{T}=1.61$ as estimated by Cloyne (2013) using narrative data on tax changes. ${ }^{28}$ To obtain tax multipliers from (four) estimated SVARs, we convert estimated elasticities (since our variables are expressed in logarithm terms) into multipliers via ex post conversion factors. For each sample size and value of $\alpha_{Y}^{T}$, we convert the elasticity into multipliers using the minimum, the mean and the maximum value of the average of the ratio GDP/T of the sample size under analysis. ${ }^{29}$ The

combining the estimation of elasticity of tax revenues to their tax base with the elasticity of tax base to output. Corporate and indirect taxes is equal to 1 by assumption. Moreover, the computation of the automatic stabilizer excludes output elasticity to GDP cyclical effects on tax expenditure, income of self-employed, capital gains, for example. See Perotti (2005) and Mertens and Ravn (2014) in-depth analysis.

${ }^{26}$ Our results are robust to the alternative specification that government spending "comes first" than tax shock. The results are available upon request.

${ }^{27}$ All SVARs are estimated including a constant and a linear time trend.

${ }^{28}$ The exercises on two samples are justified because the Perotti's output elasticity of taxes is calibrated for the period 1963:I to 2001:II, whereas the estimation of Cloyne is related to the sample 1955:I-2009:IV.

${ }^{29}$ For the sample size 1963:I-2001:II the mean, minimum and maximum of the ratio GDP/T 
$90 \%$ confidence intervals are computed using 10,000 bootstrapped replications. Figure A.1 depicts the IRFs. The top panels show the response of output to a tax shock for the period 1963:I to 2001:II, whereas the bottom ones for the period spanning from 1955:I to 2009:IV. The left-hand side panels depict the results for the two different samples when $\alpha_{Y}^{T}=0.76$ (Perotti), whereas the right ones when $\alpha_{Y}^{T}=1.61$ (Cloyne). Each plot reports the point estimates multiplied by different conversion factors: the mean (blue line), the minimum (red line), and the maximum (dotted red line). Figure A.1 shows that, for each sample size, increasing the value of $\alpha_{Y}^{T}$ the expansionary effects of a cut in taxes on output increase. Moreover, the value of $\alpha_{Y}^{T}$ has an impact on the persistence of the shock. That is evident whether we consider table A.1 which reports the cumulative multipliers, for different sample sizes, coefficient restrictions, and conversion factors. Let us focus on the sample size A (1963:I -2001:II) and on the row reporting tax multipliers using as conversion factor the mean of GDP/T, mean (A). The estimated 1-year integral multiplier (4Q) is -0.3 setting $\alpha_{Y}^{T}=0.76$, whereas doubles setting $\alpha_{Y}^{T}=1.61$. Moreover, the value of $\alpha_{Y}^{T}$ has effects on the persistence of the shock. Indeed, whereas the 2-year integral multiplier (8Q) tax multiplier is not statistically significant for $\alpha_{Y}^{T}=0.76$, it is for $\alpha_{Y}^{T}=1.61$. Turning on panel $\mathrm{B}$, the 1-year integral tax multiplier (4Q) is statistically significant only when $\alpha_{Y}^{T}=1.61$. Further, using a different value of conversion factors affects the size of output tax multipliers. For example, this bias is evidence focusing on the 2-year integral multipliers (8Q) of panel A, for which tax multipliers range below and above one.

The results show that using the same dataset, the same estimation's method but different coefficient restrictions on the output stabilizer yield different results. This is consistent with Caldara and Kamps (2008): the fiscal multipliers change according to the calibration of the output elasticity of taxes. Moreover, the combination of coefficient restrictions with the value of ex post conversion factors may lead to other bias on tax multiplier estimates.

An exogenous tax change measure based on the narrative method does not require imposing restrictions on the output elasticity of taxes. A solution to avoid ex post conversion problem is to convert GDP and taxes to the same units ex ante the estimation. Hence, we identify the tax shock via the tax shock measure proposed by proposed by Cloyne (2013), and to avoid bias on tax multipliers we transform the variables as in Hall (2009), Barro and Redlick (2011) and Owyang,

are 3.19, 2.83 and 3.9, respectively. Regard to the sample size 1955:I to 2009:IV, the mean, minimum and maximum of the above ratio are $3.25,2.83$ and 4.02 , respectively. 
Ramey, and Zubairy (2013).

Figure A.1: Perotti and Cloyne's output elasticity of revenues in a SVAR specification
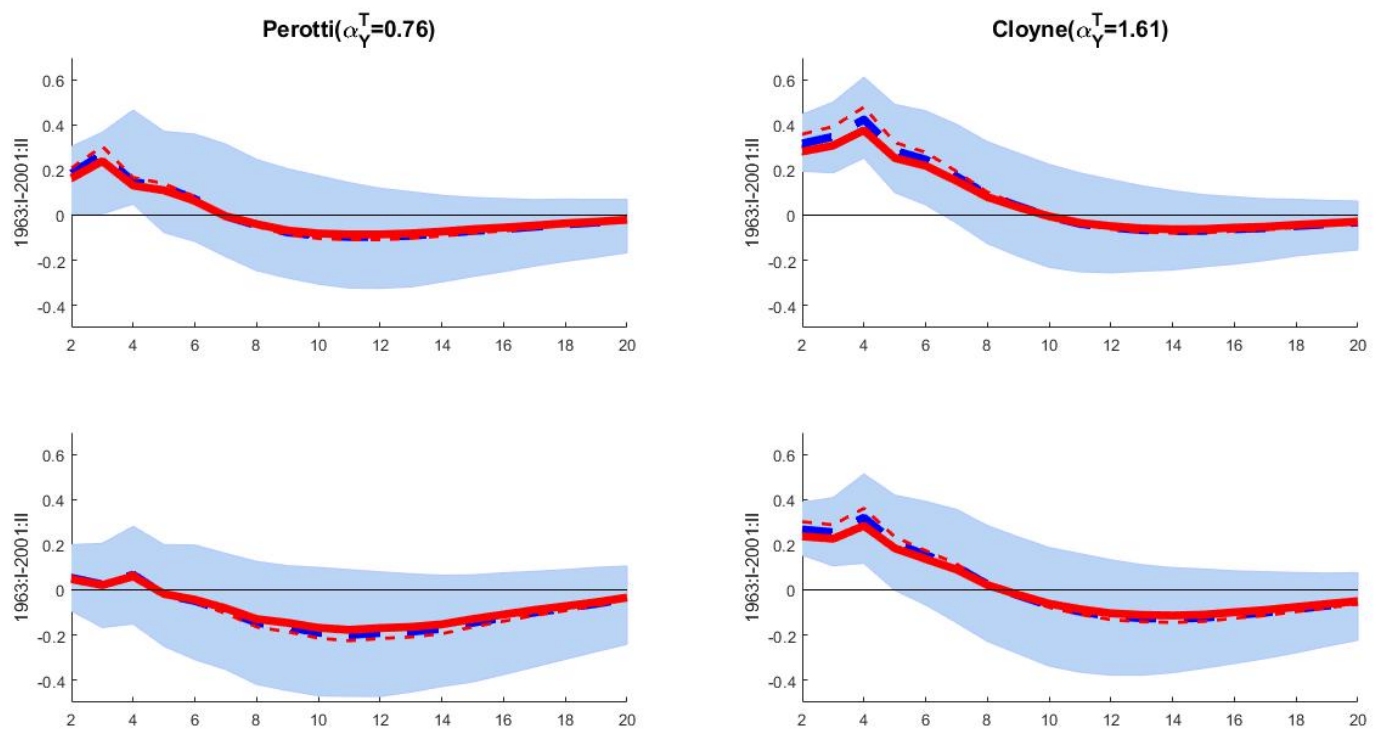

Notes: Top panels show the response of output to a tax shock for the period 1963:I to 2001:II, whereas the bottom panels the one for the period 1955:I-2009:IV. The left panels refer to the case in which the output elasticity is set to 0.76 Perotti (2005), whereas the right ones refer to an automatic stabilizer set to 1.61 Cloyne (2013). The blue, red and dotted red lines depict the IRFs obtained using as ex post conversion factor the average, the minimum and the maximum of the ratio of GDP to revenues, respectively. 
Table A.1: Multipliers estimated relying on different sample size, coefficient restrictions, and conversion factors

\begin{tabular}{cccccc}
\hline \hline Sample size & CF & \multicolumn{2}{c}{ Perotti } & $\left(\alpha_{Y}^{T}=0.76\right)$ & \multicolumn{2}{c}{ Cloyne $\left(\alpha_{Y}^{T}=1.61\right)$} \\
\hline & & $4 \mathrm{Q}$ & $8 \mathrm{Q}$ & $4 \mathrm{Q}$ & $8 \mathrm{Q}$ \\
& & & & \\
(A) 1963:I-2001:II & $\min (\mathrm{A})$ & $\mathbf{- 0 . 2 2}$ & -0.39 & $\mathbf{- 0 . 5 6}$ & $\mathbf{- 0 . 8 8}$ \\
& $\operatorname{mean}(\mathrm{A})$ & $\mathbf{- 0 . 3 0}$ & -0.44 & $\mathbf{- 0 . 6 2}$ & $\mathbf{- 1 . 0 0}$ \\
& $\max (\mathrm{A})$ & $\mathbf{- 0 . 3 7}$ & -0.55 & $\mathbf{- 0 . 7 9}$ & $\mathbf{- 1 . 2 4}$ \\
& & & & \\
(B) 1955:I-2009:IV & $\min (\mathrm{B})$ & -0.06 & 0.05 & $\mathbf{- 0 . 4 0}$ & -0.59 \\
& $\operatorname{mean}(\mathrm{B})$ & -0.07 & 0.06 & $\mathbf{- 0 . 4 8}$ & -0.67 \\
& $\max (\mathrm{B})$ & -0.09 & 0.07 & $\mathbf{- 0 . 6 0}$ & -0.83 \\
\hline \hline
\end{tabular}

Notes: Top rows show the response of output to a tax shock for the period 1963:I to 2001:II, whereas the bottom rows the one for the period 1955:I-2009:IV. The left column refers to the case in which the output elasticity is set to 0.76 Perotti (2005), whereas the right ones refers to an automatic stabilizer set to 1.61 Cloyne (2013). Bold numbers indicate the coefficients statistically significant at $90 \%$.

\section{References}

Barro, B. J. and C. J. Redlick (2011). "Macroeconomic Effects from Government Purchases and Taxes". Quarterly Journal of Economics 126(1), pp. 51-102. Blanchard, O. and R. Perotti (2002). "An Empirical Characterization of the Dynamic Effects of Changes in Government Spending and Taxes on Output". Quarterly Journal of Economics 117(4), pp. 1329-1368.

Caldara, D. and C. Kamps (2008). "What are the Effects of Fiscal Policy Shocks?" ECB WP 0877/ March.

Cloyne, J. (2013). "Discretionary Tax Changes and the Macroeconomy: New Narrative Evidence from the United Kingdom". American Economic Review 103(4), pp. 1507-1528.

Giorno, C., P. Richardson, D. Roseveare, and P. van den Noord (1995). "Potential Output, Output Gaps and Structural Budget Balances". OECD Economic Studies, No. 24, Paris. 
Hall, R. E. (2009). "By How Much Does GDP Rise If the Government Buys More Output?" Brookings Papers on Economic Activity, Economic Studies Program, Brookings Institution, pp. 183-249.

Mertens, K. and M. O. Ravn (2014). "A reconsiliation of SVAR and the Narrative Estimates of Tax Multipliers". Journal of Monetary Economics 68, S1-S19. Owyang, M., V. A. Ramey, and S. Zubairy (2013). "Are Government Spending Multipliers Greater During Periods of Slack? Evidence from 20th Century Historical Data". American Economic Review Papers and Proceedings 103(3), pp. 129-134.

Perotti, R. (2005). "Estimating the Effects of Fiscal Policy in OECD Countries". CEPR Discussion Paper 4842.

Romer, C. and D. Romer (2010). "The Macroeconomic Effects of Tax Changes: Estimates Based on a New Measure of Fiscal Shocks". American Economic Review 100, pp. 763-801.

van den Noord, P. (2002). "Automatic Stabilizers in the 1990s and Beyond".

Buti, M., von Hagen, J., Martinez-Mongay, C. (Eds.), The Behavior of Fiscal Authorities: Stabilization, Growth and Institutions, Palgrave. 


\section{B Appendix}

\section{Business cycle identification via BQQ}

There is not in the UK an official dating Committee, as the NBER, which has established an expansion and recession chronology and which has been recognized as an authoritative dating of the cycle. ${ }^{30}$ The NBER (2001) defines a recession as "a significant decline in activity spread across the economy, lasting more than few months, visible in industrial production, employment, real income, and wholesale-retail trade. A recession begins just after the economy reaches a peak of activity and ends as the economy reaches its trough". According to the literature, turning points can be defined in terms of the absolute decline in output (classical cycle) or in terms of deviation of GDP growth rate from its trend (deviation cycle). The deviation-from-trend approach, as in Cooley and Prescott (1995) and Stock and Watson (2008), requires detrending a series. However, several detrending methods exist. For example, the NBER uses the phase-average trend method (PAT), the macroeconomists use Hodrick-Prescott filter or the "band pass" to remove deterministic/stochastic trend. According to Canova (1998) the identified business cycle may depend on the filter used. Moreover, Harding and Pagan (2002) highlight that smoothing methods are aimed at simplifying turning point identification removing idiosyncratic variation. Thus, if turning points are detected using quarterly data series the utility of smoothing methods decreases with such frequency data. Hence, we identify turning points relying on the classical cycle approach. We use the dating algorithm proposed by Harding and Pagan (2002) which is the quarterly version of the well-known monthly Bry and Boschan (1971) algorithm. ${ }^{31}$

The BBQ algorithm isolates local minimum and maximum points in a quarterly series, via some constraints. First of all, a local peak (trough) occurs at time $t$ when

$$
y_{t}>(<) y_{t \pm k}
$$

where $\mathrm{k}=1,2, . . \mathrm{K} . \mathrm{K}$ allows $y_{t}$ to be a local local peak (trough) to two quar-

\footnotetext{
${ }^{30}$ In 2002 CEPR established a Business Cycle Dating Committee for the euro area.

${ }^{31}$ The BBQ is one of the most widespread algorithms in detecting turning points. For example, Artis, Marcellino, and Proietti (2002) rely on the BBQ to analyze the characteristic of the business cycle. However, there are other algorithms that we may use to date turning points, for example a Markov Switching model Hamilton (1998). As pointed out by Harding and Pagan (2002) the Markov Switching model depends on the relative statistical framework.
} 
ters on either side. ${ }^{32}$ Secondly, the phases alternate between peak and trough. This because whether the phases alternate, then it is possible to distinguish the phase of recession (from peak to trough) from the expansion one (from trough to peak). ${ }^{33}$ Thirdly, a complete cycle (from peak to peak or from trough to trough) lasts at least $n$ quarters. The last two rules are known as censoring rules.

To verify the validity of the BBQ a natural exercise is to apply the algorithm to the US for which exists an official chronology. We set for the US $k=2$ and the duration of the complete cycle to five quarters, as in Harding and Pagan (2002), and we apply the algorithm to the log-real GDP. Then, the turning points are compared with the NBER data. Figure B.1 plots the NBER turning points (red lines) versus the turning point identified by the BBQ ones (shaded area).

Figure B.1: US Business Cycle Chronology (NBER vs BBQ algorithm)

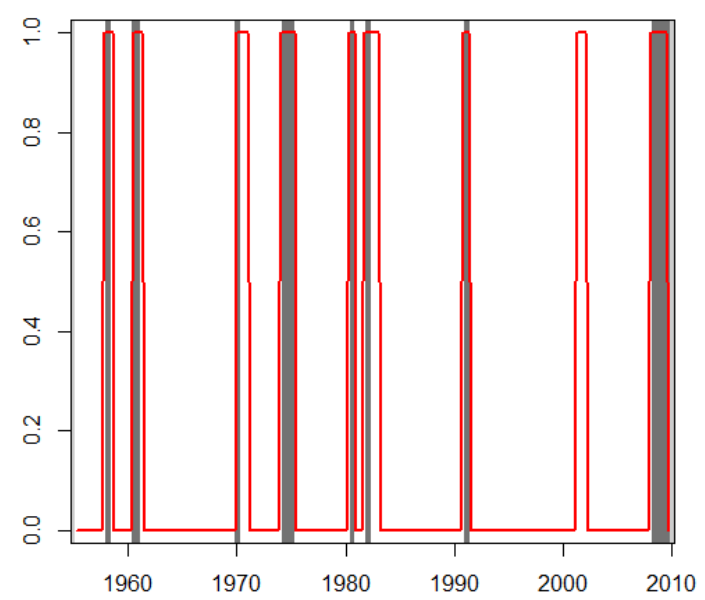

Notes: The shaded area indicate the recession phases identified by the BBQ algorithm, whereas the red lines show the NBER business cycle chronology. The sample size spans from 1955:I to 2009:IV

From 1955 to 2009 the NBER has recorded 9 recessions, whereas the algorithm does not capture the turning points of 2001. Stock and Watson (2010)

\footnotetext{
${ }^{32}$ Notice that larger is the value of $\mathrm{K}$ the more restrictive is the definition of the turning points (Harding, 2008).

${ }^{33}$ Harding (2008) show that in the UK the frequency of non-alternating turning points is four times higher than the US
} 
report that the NBER committee for dating relies on the quarterly real GDP and on four monthly variables, such as real personal income less transfer, real manufacturing, wholesale retail trade sales, industrial production, and nonfarm employment. They highlight that those series do not receive the same weight in the dating procedure. Moreover, Harding (2003) shows that the procedure and variables used by the NBER for the business cycle chronology have changed over time. Also, Harding (2008) report that in detecting the turning points the NBER uses not only the committee's procedure but also a voting procedure that can complicate the perfect matching of the BBQ dating turning points with the NBER one. Thus, some differences between the two procedures may be due to such reasons. Apart of the turning point of 2001 that is not captured because it does not exhibit two quarters of negative growth (Harding, 2008) and keeping in mind the above problems, our exercise reproduces the turning points from the NBER. Overall, the BBQ algorithm performs well on the US. After having run the above test, we apply the BBQ algorithm to the UK.

Figure B.2: UK Turning Points

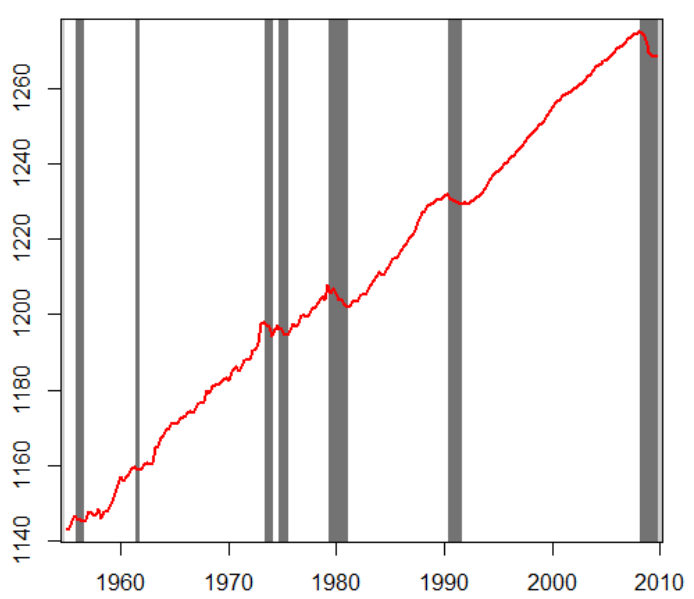

Notes: The shaded area indicate the UK recession phases (1955:I-2009:IV) identified by the application of the BBQ algorithm on the log-real UK GDP (red line).

We apply the BBQ algorithm to log-real GDP and we set $k=2$ and fix the duration of the business cycle to four quarters differently from the US exercise. 
This because Harding and Pagan (2002) find difficulties to identify for the UK the strong downturn of 1974 with a complete cycle of five quarters. The recession of 1974 was characterized by a complete cycle of 4 . Hence, for the UK a duration of the complete cycle of four can be applied. Figure B.2 shows the identified turning points for the UK via the application of BBQ algorithm to the log-real GDP. From 1955 to 2009 we identify seven recessions. The number of UK recessions identified via the BBQ matches that ones reported from the Bank of England in the Inflation Report (Bank of England (2014)). The only exception concerns the recessions of the 1970s that are treated as a single recession by the Bank of England. The turning points identified by the BBQ algorithm is going to be used as benchmark for studying the state-dependent tax multiplier.

\section{References}

Artis, M., M. Marcellino, and T. Proietti (2002). "Dating the Euro Area Business Cycle". EUI WP ECO 2002/24.

Bank of England (2014). "Inflation Report". EUI WP ECO 2002/24.

Bry, G. and C. Boschan (1971). "Cyclical Analysis of Time Series: Selected Procedures and Computer Programs". National Bureau of Economic Research, New York.

Canova, F. (1998). "Detrending and Business Cycle Facts". Journal of Monetary Economics 41(3), pp. 475-512.

Cooley, T. F. and E.C. Prescott (1995). "Economic growth and business cycle". Frontiers of the Business Cycle Research, Princeton University Press, Princeton, NJ.

Hamilton, J. D. (1998). "A New Approach to the Economic Analysis of Nonstationary Time Series and the Business Cycle". Econometrica 41(3), pp. 357384 .

Harding, D. (2003). "Essay on the Business Cycle". PhD Thesis Yale University.

Harding, D. (2008). "Detecting and Forecasting Business Cycle Points". MPRA 33583.

Harding, D. and A.R. Pagan (2002). "Dissecting the Cycle: A methodological Investigating". Journal of Monetary Economics 49(5), pp. 365-381. 
Stock, J. and M. Watson (2008). "Business Cycle Fluctuations in US Macroeconomic Time Series". In: Handbook of Macroeconomics, 1. (Ed.) by J.B. Taylor and M. Woodford. Elsevier Science B.V.

Stock, J. and M. Watson (2010). "Indicators for Dating Business Cycles: CrossHistory Selection and Comparisons". American Economic Review: Papers and Proceeding 100(4), pp. 16-19. 


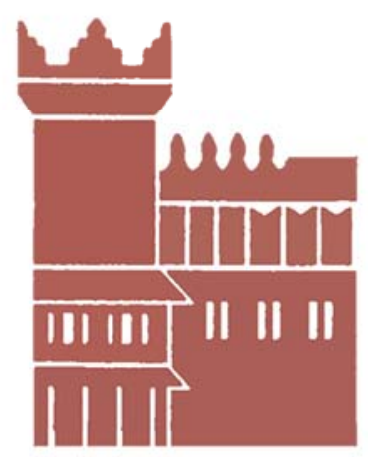

Alma Mater Studiorum - Università di Bologna DEPARTMENT OF ECONOMICS

Strada Maggiore 45

40125 Bologna - Italy

Tel. +39051 2092604

Fax +390512092664

http://www.dse.unibo.it 